\title{
قياس رأس المال الفكري بأستخدام بطاقة الاداء المتوازن لزيادة القيمة في الوحدات الحكومية/ دراسة تطبيقية في جامعة (رابرين)
}

\author{
بصيرة مجيد نجم، كلية الادارة و الاقتصاد/ جامعة سليمانية، إقليم كوردستان -العراق \\ dr.najm1976@gmail.com
}

هيرش فتح اللة احمد، كلية الادارة و الاقتصاد/ جامعة سليمانية، إقليم كردستان -العراق

heershfathulla@raparinuni.org

\begin{abstract}
ملخص
شاهد العالم المعاصر في السنوات الأخيرة تقدما متسارعا في النواحي التكنولوجية، ويعود ذلك إلى الدور الكبير الذي مارسه العنصر البشري في هذا التقدم باعتباره احد عوامل الإنتاج المساهمة في العملية الإنتاجية، وعلى ضوء ذلك تهدف البحث الحالي استخدام احدى التقنية (بطاقة الاداء المتوازن) لغرض قياس رأس المال الفكري في الجامعة ومعالجته محاسبا وإظهارها في القوائم المالية. ولغرض وصول الى اهداف البحث اعتمدت البحث على البيانات والمعلومات التي حصلت عليها الباحث من الجامعة، تم استخدم المنهج الوصفي والتحليلي لغرض جمع البيانات وللصول الى نتائج البحث. من اهم استنتاجات البحث هو أن بطاقة الأداء المتوازن اسلوب حديث لمتابعة التقدم المحرز نحو بلوغ الأهداف الاستراتيجية , كما هي ليست مجرد أداة لقياس ولكنها اسلوب متعدد الأبعاد يتطلب إدارة لتحديد الاستراتيجية من الناحية التنفيذية وفهم العلاقة بين العمل المنجز في جميع مستويات المؤسسة والأهداف الاستراتيجية, و استخدام هذه الأداة لغرض قياس رأس المال الفكري هو هدف البحث الحالي، رأس المال الفكري هو المحرى الأساسي لكافة الأعمال والأنشطة التي تقوم بها المؤسسة ، فضلا عن دوره في تحقيق أهدافها المتنوعة في زيادة طاقتها الإنتاجية وتحقيق الميزة التنافسية. و توصى البحث الحالي, على المؤسسات الحكومية إيجاد الوسائل والإجراءات المناسبة التي تساعدها في تحقيق عملية القياس والإفصاح المحاسبي عن رأس المال الفكري في قوائمها المالية الختامية, يتعين على المؤسسات الحكومية عدم تحميل كامل قيمة رأس المال الفكري على حساب النتيجة لأن رأس المال الفكري يعد من الموجودات المؤسسة وليس من مصاريفها.
\end{abstract}

\section{كلمات مفتاحية}

رأس المال الفكري,بطاقة الاداء المتوازن, القياس المحاسبي. 


\section{أ- مفهوم رأس المال الفكري.}

ازدادت الأهتمام بالرأس المال الفكري منذ التسعينات القرن الماضى,و نتيجة حداثة هذا الموضوع, فأنه ليس هناك اتفاق واضح بين العلماء و الباحثين حول مفهومها. حيث يرى (Oster Land) أن رأسمال الفكرى هو نوع من انواع موجودات غير ملموسه و صورة من صور رأسمال المعرفي. كما يشير(Elper) الى تعبير اخر, بان رأسمال الفكرى يلعب دورا متكاملا مع ادارة المعرفه, و هذا الدور يظهر في المشاركة الفعاله في تحقيق الميزه التنافسيه و التطوير التنظيمى, و يتحقق هذا من خلال التفكير الإستراتيجى لادارة الموارد الفكريه في المؤسسة.

و يعد التفكير الإستراتيجى الأساس لرأس المال الفكرى حيث يتسم التفكير الاستراتيجى بالحداثة على مستوى التأطير والتطبيق يعد من الموضوعات البكر التى ما زال الغور فيها بين الندرة والمحدودية مما يجعل الكثير من مفاهيمه وابعاده لم تحسم على مستوى الفكر والتنظير حيث يجعل الفكر والإبداع والإقتراع الابداعى التقنى لرأس المال الفكرى دور متعاظم واهمية استراتيجية فى ظل متطلبات العصر الحديث. كما تتمثل تلك المتطلبات فى الآتى : 1.تمكن المؤسسة من إختيار الطريقة المناسبة لقياس وتقييم رأس المال الفكرى التى تحقق أهدافها الإستراتيجية الداخلية والخارجية. 2.يحقق التوظيف الأمثل لموارد المشروع (تنظيمية ،مادية ، علائقية ،هيكلية ونقدية ) مما يحقق أعلى قيمةمضافة للمؤسسة . 3. (Andersissen.D,2004,p20). تقليل الفجوة التنافسية لقيمة رأس المال الفكرى للمؤسسة مع المنافسين 4.قياس فاعلية الإستثمار فى عناصر رأس المال الفكرى ومدى تحقيقها للأهداف الإستراتيجية للمؤسسة. ولم تعد رأس المال الفكري كلمة عامه انما هي مصطلح معروف ومطبق في العديد من المؤسسات الاقتصادية والاجتماعية التي تتفاوت درجة نجاح بعضها عن الاخري وتنفق ملايين الدولارات علي تطبيق ادارة رأس المال بما يساعد علي حشد الافراد والبنية التحتية تطوير المؤسسة والعمليات الخاصة بها بالاضافه الي توفر التقنيات الحديثة مما يساعد علي سرعة وكفاءة اتخاذ القرارات في ظل التغيرات الاقتصادية وزيادة حدة المنافسة علي المستوي المحلي والدولي ، لذا اصبحت رأس المال موردا استراتيجيا يتنامي بثكل تراكمي ويؤثر بثكل كبير علي المركز التنافسي للمؤسسة. اذ ان رأس المال الفكري يتمثل في المعرفة والمعلومات وحقوق الملكية الفكرية والخبرات التي توظفها لانتاج الثروه وتدعيم القدرات التنافسيه ويعتبر مصدر لخلق الثروة ويمثل موجودا غير ملموسة كما يتضمن الرصيد المعرفي الناتج من الابتكار والبحث العلمي · (التجاني,2013,ص67) 
يرى اغلبية الباحثين ان المعلومات المحاسبية لها دور محدد في اتخاذ القرارات من قبل المستثمرين و تحديد القيمة السوقية للمؤسسة و بالاخص المؤسسات التى تستثمر مبالغ كبيرة في استثمار الموجودات غير الملموسة و لاتسجل هذه المبالغ في الدفاتر كموجودات غير ملموسه, مثل (تكاليف البحث و التطوير, الشهرة الداخليه, تطوير العلاقات). بالرغم من ان هذه الموجودات غير الملموسة يساهم في ارتفاع القيمه السوقيه للمؤسسة.( الخيال, 2005,ص 11) مع مرور الزمن و ادراك المؤسسات باهمية رأس المال الفكرى و دوره الكبير الذى يلعبه في خلق الميزة التنافسيه ادى ذلك الى الاهتمام الكبير بدراسة مكونات راس المال الفكري و طرق قياسه و الافصاح عنه مما يؤدى الى مساعدة الادارة في الاهتمام بها و تنميتها و الاحتفاظ بها. كما انه يساهم في تحقيق هدف المؤسسة الا و هى تحقيق الميزه التنافسية و ارتفاع سعر الاسهم في السوق, و يساعد على ان تعطى المستثمرين الحالين المعلومات الافضل لغرض تقليل التكاليف الى الحد الادنى. اصبح رأس المال الفكرى المكون الاساسى للمؤسسات و امكانيه الاستثمار فيها له دور كبير على استمرارية المؤسسة و تطويرها و خلق قيمه المضافه للمؤسسة و تحقيق الميزه التنافسية و مساهمتها في الاستمرارية و التطوير.

و يعتبر الموجود غير الملموس و بالاخص رأس المال الفكري اهم الموجودات في ظل اقتصاد المعرفة لأنه يمثل القدرة العقلية التى تدخل التعديلات على مدخلات المؤسسة بواسطه الابتكارات الناتجة عن جهود الموارد البشريه من المهارات والتدريب.| الجندي,2005, ص118)

ان المعايير المحاسبيه الدوليه يتم الاعتراف بالموجودات غير الملموسة في نطاق صغير( ايى عند شراء هذا النوع من الموجود), اى ان المعلومات المحاسبيه ليس مفيدا جدا في تحديد اسعار اسهم المؤسسات التى تصرف مبالغ كبيرة في الموجودات غير الملموسه و لا تسجل في دفاترها كموجود غير ملموس. يمكن ان نستخلص اهميه رأس المال الفكرى فيما يلى:1- رأس المال الفكرى يعتبر من اهم الموجودات التى تلعب دورمهما في تعظيم موجودات المؤسسة و خلق القيمه لها و امكانية تطويرها و استمرارية المؤسسة و بقائها في الميدان المنافسة. 2- يعتبر رأس المال الفكري الثروة القومية الحقيقية التي يتميز بها اي مجتمع و التي يتكون من المهارات والخبرات المتراكمة و كفاءات و قدرته على خلق الثروة. 3- في ظل المخاطر الاقتصادية و المتقلبات التى تحدث في عصرنا الحالى تظهر اهمية رأس المال الفكري في تخطيط خطط الاستراتيجية الطويلة و القصيرة المدى. 
5- العلاقات هو مكون رئيسى لرأس المال الفكري التى يرتبط المؤسسة بالعملاء و ايجاد زبائن جديدة. 6- الاهمية الكبرى لرأس المال الفكري تظهر في حال وضع الخطط الاسترتيجية للمؤسسة و وضع الميزانيات التقديريه و كيفية استخدام هذا الميزانيه بأسهل وسيله و اقل تكلفة في انتاج مخرجات متطور. 10-تتفير اهمية الرأس المال الفكرى من مكان الى مكان اخر و يظهر في البيئة التى يعمل فيها. (عمر,حمدي, 2011,ص5)

\section{ت- خصائص رأس المال الفكرى.}

$$
\text { يتميز رأس المال الفكري بعديد من الخصائص يمكن تحديد بالاتي :- }
$$

1- الميزة الاساسيه لرأس المال الفكرى هى انه غير ملموسة و غير مادية.

2- موقع التواجد لراس المال الفكرى هى داخل عقول الافراد العاملين في المؤسسة

$$
\text { 3- يتمثل راس المال الفكرى في الافراد ذو المعرفة و الخبرات. }
$$

4- راس المال الفكرى يتزايد قيمتها بالخبرات والابتكارات و الاختراعات.

$$
\text { 5- يتمثل الرأس المال الفكرى بصعوبه قياسها بدقه. }
$$

6- لها ميزة استثنائيه و هى يتوقد عند حدوث المشاكل.

7- له تأثير كبير على القرارات الاستراتيجيه للمؤسسة.(مصدر سابق,ص 6-7)

\section{ث- مكونات رأس المال الفكرى.}

كما هناك اختلافات حول تعريف رأس المال الفكرى ايضا هناك اختلافات حول عناصر و مكونات رأس المال الفكرى, حيث من وجه نظر ( ستيوارت), يتكون رأس المال الفكرى من ثلاثة عناصر رئيسيه و هى: (رأس المال البشرى, رأس المال الهيكلى, رأس المال العملاء). و هي كالاتي: (Stewart, T.1997)

1-رأس المال البشري (Human Capital) :يتضمن المهارات والخبرات والمقدرة العقلية فهو مصدر للتجديد والابتكار. 2-رأس المال الهيكلي (Structural Capital) :يتمثل بالأنظمة المعلوماتية وبراءات الاختراع وقواعد البيانات . 3-رأس المال الزبائني (Customer Capital):الذي يتمثل بالمستهلكين لمنتج ما ومدى ولائهم لهذا المنتج · 


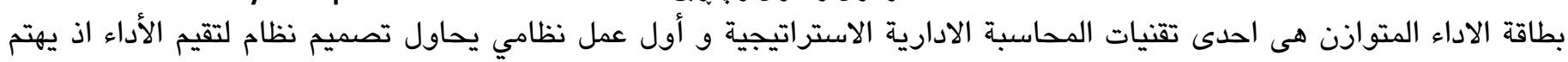
بترجمة الاستراتيجية المؤسسة الى أهداف محددة و مقاييس و معايير مستهدفة و مبادرات للتحسين المستمر, كما انها توحد جميع المقاييس التي تستخدمها المؤسسة, حيث يتميز هذا الأسلوب عن غيره من أساليب الرقابة وقياس و تقويم الاداء في جمع بين مقاييس الأداء المالي و مقاييس الأداء غير مالي التي تتصف بسهولة تتبعها و ربطها باستراتيجية المؤسسة. يمكن تعريف بطاقة الأداء المتوازن بأنها:" نظام إداري يهدف إلى مساعدة الملاك والمدريين على ترجمة رؤية و استراتيجيات شركاتهم إلى مجموعة من الأهداف و القياسات الإستراتيجية المترابطة. وذلك من خلال الاعتماد على بطاقة الأداء المتوازن،حيث لم يعد التقرير المالي يمثل الطريقة الوحيدة التي تستطيع المؤسسات من خلالها تقييم أنشطتها ورسم تحركاتها المستقبلية. (المغربي,2009) ص 57)

\section{ح-مكونات بطاقة الأداء المتوازن.}

يتكون بطاقة لاأداء المتوازن فيما يلي:

1-الرؤية المستقبلية: هي التي تبين إلى أين تتجه المؤسسة وتوضع صورتها المستقبلية. 2-الإستراتيجية: وهي التي تتكون من مجموعة الإجراءات والأفعال لتحقيق الأهداف أو خطط الأهداف التي قامت المؤسسة بتحديدها. 3-المناظير هي مكون يدفع باتجاه تبني إستراتيجية معينة وفقا لمؤشرات تحليل مهمة ومن ثم العمل على تنفيذ هذه الإستراتيجية للوصول إلى المؤشرات الواردة في هذا البعد وهناك أربعة أسس في بطاقة الأداء المتوازن هي البعد المالي، بعد العملاء (الزبائن) بعد العمليات الداخلية، وبعد النمو والتعلم وهو عنصر رئيسي في الإستراتيجية. 4-الأهداف: هو غرض الإستراتيجية التي تبين كيفية تنفيذها ويعبر عنها بالمستويات المحددة والقابلة للقياس لتحقيق الإستراتيجية. 5-المقاييس: تعكس قياس التقدم باتجاه الأهداف وتكون ذات طابع كمي وتوصل القياسات إلى الأعمال المطلوبة لتحقيق الهدف ويصبح الكثف الممكن وضعه على شكل فعل لكيفية تحقيق الأهداف الإستراتيجية فهي عبارة عن تنبؤات عن الأداء المستقبلي وهي التي تدعمه تحقيق. 6-المستهدفات: تمثل البيانات والتصورات الكمية لمقاييس الأداء في وقت ما في المستقبل. 7-رتباطات السبب والنتيجة: تعبر عن علاقات الأهداف وارتباط كل منها بالآخر وتكون مشابهة لعبارات (إذا - إذن)حيث تكون واضحة وجلية.

8- المبادرات الإستراتيجية: هي برامج عمل توجه الأداء الإستراتيجي وتسهل عملية التفيذ والإنجاز على المستويات التظيمية الدنيا. و اخرون, 2009, ص ص 154-155) 
يهتم هذا المنظور بتحليل قدرة العاملين بالمؤسسة على التعلم والتطور والبحث وتحسين القدرة التنافسية مقارنة بما يحققه المنافسون , ومدى قدرة المؤسسة على توظيف المعرفة والخبرات المتراكمة , وهل تتعلم من أخطائها و كيف تستطيع أن تجعل قدراتها على التفيير والتطوير مستمرة. ويبين هذا المنظور الفجوة بين القدرات الحالية والقدرات المطلوبة للوصول إليها مما يجعل المؤسسة تحاول تقليل هذه الفجوة من اجل تحقيق الأداء المطلوب عن طريق إعادة تدريب العاملين, تحسين مستوى التكنولوجيا في الأنظمة الموجودة بالمؤسسة, إعادة وصف الإجراءات التنظيمية داخل الوحدة, والتحفيز والتحسين المرتبط بالعاملين لدعم التوجه الاستراتيجي. ويحدد هذا المنظور القدرات التي يجب أن تنمو فيها الوحدة من اجل تحقيق عمليات داخلية عالية المستوى بحيث تخلق قيمة للزبائن والمجتمع, وذلك من خلال تحسين العمليات التشغيلية باستمرار وتقديم خدمة متميزة وخلق قيمة اكبر للزبائن.( محمود,2013, ص29)

\section{2- منظور الممليات الداخلية:}

يركز هذا المنظور على العمليات الداخلية المهمة التي تمكن المؤسسة من التميز و التي سيكون لها الأثر الأكبر وتحقيق رغباتهم وتحقيق الأهداف المالية للمؤسسة بشكل مرضي على رضا الزبائن للعاملين فيها, و اذ يتعين على الوحدات أن تقرر ما هي العمليات والكفاءات التي يجب أن تتفوق فيها لتنفيذ الإستراتيجية وتحديد المقاييس لكل منهما. ويهتم هذا المنظور أيضا بقياس الأداء المستقبلي للمؤسسة من خلال عرض الأنشطة والعمليات الداخلية التي تنفذها المؤسسة لتحقيق أهدافها ومتطلبات الزبائن, أي أهداف إدارة المؤسسة والمجتمع والزبائن, وذلك من خلال الاستحداث والابتكار والتطوير في ضوء محددات المجتمع, وتثخيص احتياجات الزبائن ودورة التشغيل التي تركز على تقديم الخدمات للزبائن بهدف رفع درجة رضاهم وخدمتهم. وبصورة عامة فإن الأهداف الرئيسة لهذا المنظور هي تحسين العمليات والعلاقات مع الزبائن, وتقيسم سلسلة الأنثطة و المراحل الداخلية للوحدات التي تحدث القيمة المجزة وهي الابتكار والإبداع, والتشغيل للزبون على ثلاث دورات كما هي مقترحة من قبل وخدمات ما بعد البيع, والتي تمثل سلسلة القيمة الداخلية للمؤسسة, ويقصد بسلسلة القيمة نظام متماسك ومتكامل من الأنشطة الإنتاجية التي تسهم في إنتاج السلع والخدمات, اذ أن الترابط المتسلسل ما بين هذه الأنثطة يؤدي لى التأثير على بعضها بعض من خلال التكلفة وفاعلية إنتاجها, ومن المهم جدا أن توفق المؤسسة ما بين هذه الأنثطة وفقا للطريقة الإستراتيجية المثلى التي تحقق ميزة تنافسية. (علاء, : 2010, ص ص 13-14)

3- 3ن منطور الزبائن:

يركز هذا المنظور على الزبائن والأسواق التي تطرح المؤسسة فيها إنتاجها, اذ يتم هنا تحديد مقاييس أداء المؤسسة والاحتفاظ بالزبائن في هذا المجال ـ وتتركز هذه المقاييس حول رضا الزبائن والحصول على زبائن جدد الحاليين وربحية الزبائن والحصول 
على حصة جديدة في السوق وترتبط هذه المقاييس بمحددات الزبون ذات العلاقة بالوقت , والجودة, والأداء والخدمة, والكلفة المخفضة . (حسن, محسن,2005, ص5) وهناك مجموعة من الخصائص التي تحكم محركات القيمة من وجهة نظر الزبون في المؤسسات المختلفة وهي: (عابدين, (12,2013 -سمات أو خصائص الخدمة (المنتج) ضمن جودة وكفاءة الخدمات. -العلاقة مع الزبون: وتتضمن توصيل الخدمة, ومدى استجابة الوحدة لمتطلبات الزبون -السمعة أو الثهرة: وتتمثل في قدرة المؤسسة بالتعريف عن نفسها للزبائن, وابراز السمات التي تتميز فيها عن غيرها من المؤسسات. ويساعد هذا المنظور في التعرف على الطرق التي سيتم بها خلق قيمة للزبون اذ يشكل جزءا مهما من المقاييس, فإن أخفقت المؤسسة بتقديم المنتج أو الخدمة بما يلبي احتياجات الزبون ويتكاليف مناسبة على المدى القصير والبعيد فلن تتولد إيرادات مما يؤدي إلى تدهور الوضع المالي للمؤسسة لذا من الضروري أن تتابع المؤسسة أي تغيرات في الجودة, وقت التسليم و القدرة على التسليم وأي تغيرات في أذواق واحتياجات الزبون الحالية والمستقبلية, وترجمة ذلك إلى قيمة مقترحة تؤدي إلى رضا الزبائن والاحتفاظ بهر.إذ يسأل هذا المنظور عن الكيفية التي يجب أن تكون بها المؤسسة أمام زبائنها من اجل تحقيق رؤيتها اذ إن القيمة من وجهة نظر الزبون هي عامل رئيس يجب على المؤسسة أن تسعى إلى تحقيقه وتعرف على أنها الفرق بين الإدراك والتضحية, اذ أن الإدراك هو ما يتلقى الزبون والتضحية هو مايعطي الزبون. ويتضمن الإدراك سمات مثل وظيفة المنتج, وجودة المنتج, و موثوقية التسليم, وزمن الاستجابة للتسليم, وصورته, وسمعته. وتشمل التضحية سمات مثل سعر المنتج, والوقت اللازم لتعلم كيفية استخدام المنتج, تكاليف التشغيل, تكاليف الصيانة, وتكاليف التخلص منها.(Hansen, Mowen,2006,p599)

\section{4- المنظور المالي:}

يصف هذا المنظور النتائج من الناحية المالية التقليدية إذ يعتبر من مناظر تقويم الأداء وتمثل نتائجه مقاييس موجهة نحو تحقيق الاهداف المالية والوقوف على مستوى الارباح المتحققة لاستراتيجية المؤسسة و تصنيع قيمة للمساهمين بالعمل على تخفيض مستويات التكاليف مقارنة مع تكاليف الوحدات المنافسة وبشكل نسبي, ويركز هذا المنظور أيضا على حجم مستوى الدخل التشغيلي والعائد على رأس المال المستثمر ونمو حجم المبيعات والعائد على حق الملكية والعائد على إجمالي الموجودات والقيمة المضافة ونمو التدققات النقدية المتولدة من الأنشطة التشغيلية. ويهتم المنظور المالي بالنتائج المالية لبقية المناظير الأخرى, وعليه يجب ربط أهداف ومقاييس المناظير الأخرى بالأهداف المالية فضلا عن امتالك المنظور المالي لثلاثة مواضيع إستراتيجية هي: (نمو الايراد, تخفيض الكلفة, استفلال الموجودات) والتي يمكن أن تخدم كأساس لتحسين أهداف ومقاييس تشغيلية محددة ويجيب هذا المنظور على التساؤلات الخاصة بالكيفية التي يرى فيها المساهمون وحدة الأعمال وتعكس المقاييس المالية النتائج التي تمثل الاداء المالي التاريخي لوحدات الأعمال .(مصدر سابق,ص597) 
هذا المنظور هو منظور مقترح والتي يتبين الاعتراف و القياس المحاسبي الفعلي لكل المناظير الاخرى من خلال تحويل كل الانثطة و العمليات الى ارقام حقيقية و ايجاد حلول محاسبة لقياس واعتراف المحاسبي لرأس المال الفكري استنادا الى المعيار الدولي المرقم (38) المخصص للموجودات غير ملموسة التي ينص: من الممكن الاعتراف والقياس للموجود غير ملموس اذا كان توفر لدى الموجود شرطان و هما:أ_من المحتمل تدفق المنافع الاقتصادية المستقبلية المتوقعة المرتبطة بالأصل الى المؤسسة. ب_أن يكون من الممكن قياس تكلفة الموجود بموثوقية. و تعتبر سيطرة المؤسسة على الموجود غير ملموس امرا اساسيا لتحقيق الشرط الأول للأعتراف بالموجود غير ملموس. ويتم سيطرة المؤسسة على الموجود غير الملموس من خلال وجود حماية القانونية كما هو الحال في براءات الاختراع. و بتقيم هذه الحالة من الممكن ان نستنتج بأن تتفق هذه الشروط مع واقع الجامعة من حيث ( البحوث, المجلات, الندوات, الاتفاقيات,.....) هم من ضمن سيطرة الجامعة و يمكن رسملت تكاليفهم كموجود غير ملموس.( أبو نصار, حميدات,2009,ص ص 624-633) و هناك طريقة اخرى التي اقترح من قبل باحثان (سعود جايد مثكور,جعفر فالح ناصر,2013) و التي هي طريقة المخصصات الفكرية, إذ أن هذه الطريقة المقترحة التي اعتمدت في عملية القياس المحاسبي عن رأس المال الفكري تستند إلى قياس المخصصات الفكرية والتي تعتمد على المخصصات الشهرية الفكرية التي تدفع لموظفين العاملين بالمؤسسات والتي تتمثل بالاتي:المخصصات الفكرية = مخصصات الشهادة +مخصصات الخدمة + المخصصات الفنية مما تقدم يتضح بان الباحثان اعتمدا على المخصصات المعرفية المدفوعة كرأس المال بشري، والذي سيتم قياسه والإفصاح عن قيمته في القوائم المالية للمؤسسات الاقتصادية ومن ثم اثرهذا القياس والإفصاح على قيمة المؤسسة الاقتصادية. (مشكور, ناصر,2013, (2013 المحور الثاني:

\section{القياس والتكامل بين بطاقة الاداء المتوازن و رأس المال الفكري.}

\section{أ-مفهوم عملية القياس الهحاسبى.}

قدم الباحثون في مجالات القياس تعريفات متعددة لعملية القياس, وان اختلفت الى حد ما في الشكل الا انها تتفق في المضمون. وسنكتفي بتقديم ثلاثة منها تعبرعن مدى تطور مفهوم عملية القياس المحاسبية من الناحية العملية, حتى نخرج بمفهوم مبسط لهذه العملية. وينسب أول تعريف علمى محدد لعملية القياس بثكل عام الى (Campell) الذى عرفها بما يلي (Campell,N.R.,1957,p258) (يتمثل القياس بشكل عام في قرن الاعداد بألاشياء للتعبير عن خواصها, و ذلك بناءً على قواعد طبيعية يتم اكتشافها اما بطريقة مباشرة أو بطريقة غير مباشرة). 
و أضاف (steven) بعدا رياضيا لتعريف عملية القياس فعرفها بانها: (تتمثل في المطابقة بين الخواص أو العلاقات بموجب نموذج رياضى) أما اكثر التعريفات تحديدا لعملية القياس المحاسبية فهو ما صدر في تقرير لجمعية المحاسبين الامريكين (AAA) عام 1966 الذى ورد فيه ما يلى:(AAA,1964,p47) (يتمثل القياس المحاسبى في قرن الاعداد بأحداث المنشأة الماضية والجارية والمستقبلية, وذلك بناء على ملاحظات ماضية أو جارية ويموجب القواعد المحددة).

ويعرف مجلس معايير المحاسبة المالية الأمريكية (FASB) القياس المحاسبي بأنه "عبارة عن تخصيص أرقام للأشياء أو الأحداث وفقا لقواعد محددة، كما انه عملية مقارنة تهدف إلى الحصول على معلومات دقيقة للتمييز بين بديل وآخر في حالة اتخاذ القرار". (ريتشارد و اخرون, 2006, ص 185) و من خلال تحليل التعاريف السابقة يمكن استتاج مفهوم بسيط لعملية القياس المحاسبية و هى كالاتى: (عملية القياس المحاسبية بالمفهوم العلمى هي عملية المقابلة يتم من خلالها قرن خاصية معينة هى خاصية التعدد النقدى, بشى معين هو حدث اقتصادى يتمثل فيها بعنصر معين في مجال معين هو المشروع الاقتصادى, بعنصر اخر محدد هو عدد حقيقى , في مجال اخرهو نظام الأعداد الحقيقة, و ذلك باستخدام مقياس معين هو وحدة النقد, و بموجب قواعد اقتران معينة هى قواعد الاحتساب).

$$
\text { ب - خطوات عملية القياس المحاسبية. }
$$

يتوقف مسار عملية القياس المحاسبى و تعدد خطواطها على الأغراض التى ستستخدم فيها مخرجات القياس. وعلى هذا الأساس تتفاوت وجهات نظر المحاسبين بشأن مراحل عملية القياس المحاسبى وعدد الخطوات التى تنفذ بها, وذلك تبعا لأختلاف ارائهم حول الأغراض المستخدمة فيها البيانات المحاسبية. اذ بينما يحصر البعض عملية القياس المحاسبية بمرحلتي تسجيل القياسات المحاسبية التاريخية وتخصيصها, يرى بعضهم أن عملية القياس لا تتنهى عند هذا الحد, بل تشمل عملية تشغيل ومعالجة هذه القياسات بغض النظر عن كونها تاريخية أو مستقبلية. أما بخصوص علاقة التبويب بعملية القياس المحاسبى, فيتقق المحاسبون على اعتبارهما مترابطين. و لا يكتفون باعتبار التبويب خطواة أولية في عملية القياس المحاسبى, بل يعدوهما مترادفتين حيث يقولون: " الحقيقة التى لا يمكن نكرانها, هى ان كل عملية القياس هى في الأصل عملية التبويب" , و يؤيد هذا الرأي (Steven) حين يدعو الى استخدام مصطلح قياس (Scaling) بدلا من مصطلح تبويب (Classification) بقصد ابراز البعد القياسي لعملية

$$
\text { التبويب حيث يقول (يعد التبويب العملية الاساسية في القياس). }
$$

وقد سارت جمعية المحاسبيين الامريكية(A.A.A.) في نفس الاتجاه حين أوردت في تقرير صادر عنها ما يلي : " يعد التبويب المحاسبي في الغالب نوعا من القياس المحاسبى بالرغم من عدم استخدام الأرقام في هذا القياس"(AAA, 1971, p310)

\section{ج- النكامل بين الموجودات الفكرية وبطاقة الأداء المتوازن .}


إن المؤسـســــات المتفوقة في مجال التجارة والصـــاعة وتقديم الخدمات, يجب ان لا تقف في حدود معين لعملية الانتاج وتقديم

الخدمات, بل يجب ان تزداد جهودها حتى يمكن ان تطور منتجاتها وتقديمها للزبائن, ولضـمان بقائها في الميدان المنافسـة, يجب ان تهتم بايجاد عناصـر جديدة لتجديد قدرتها. وتوجد هذه العناصـر من خلال البحث عن عناصـر الابداع والابتكار وايجاد طرق حديثة لتقديم الخدمات المتميزة للزبانها ؛ لذلك تعد الموجودات الفكرية عنصـر الإبداع الواجب امتلاكه من قبل المؤسـسـات للوصــل الى التفوق المؤســـــيـ ،وإن الموجودات الفكرية تتكون من ثلاث مكونات هي الموجودات البشــرية التي تصــف الجهود الإنســـانية ،والموجودات الهيكلية التي تصـف القدرة على تحويل هذه الجهود الإنسـانية إلى سـلع وخدمات ،و الموجودات الزبائنية أو التفاعلية مع الأطراف الخارجية ،وأيضـا تحسين وتطوير القدرات اللازمة للتكيف مع المتغيرات البيئية .وإن التوسـع في الخطط الإستراتيجية للمؤسـســة أصسبح ضـرورة حتمية لاسـتيعاب الموجودات الفكرية بجانب الموجودات المادية ،وأصــبت الموجودات الفكرية هي العنصــر الحقيقي الذي يمثل الأســـاس الذي يتم الارتكاز عليها لخلق قيمة مضـــافة للموجودات المادية وتحقيق ميزة تنافســية

(Kaplan, Nortem, 2004,) يمكن بيان جوانب التكامل بين الموجودات الفكرية وبطاقة الاداء المتوازن وكمايأتي:

\section{1-جوانب التكامل بين الموجودات الفكرية وبطاقة الأداء المتوازن}

لشمولية بطاقة الاداء المتوازن بوصفها احد الوسائل الحديثة لتزويد المدراء بالمقايس المالية وغير مالية اللازمة لقياس الاداء الاسترتيجي للموجودات الفكرية, سيتم استخدام هذه البطاقة لقياس رأس المال الفكري في المؤسسة وكذلك فإن بطاقة الأداء المتوازن اخذت بنظر الاعتبار تقدير مكونات الموجودات الفكرية داخل المؤسسة مثل عمليات التعلم والمعرفة ورضا الزبائن, فإنَّ بعد التعلم والنمو يلعب دورا في رصف ومحاذاة الموجودات الفكرية بمكوناتها في اطار إستراتيجية المؤسسة ،ولهذا فإن مكونات الموجودات الفكرية تكاد تتطابق مع أبعاد مقياس الأداء المتوازن باستثناء بعد الأداء المالي , إذ إن الموجودات البشرية تقابل بعد التعلم والنمو , كما إن الموجودات الهيكلية تقابل بعد عمليات التشغيل الداخلية , وأيضا فإن الموجود الزبائن- الناتجة من تفاعل العلاقات مع الزبائن - تقابل العلاقات مع بعد الزبائن , ويبقى بعد الأداء المالي كناتج لكل من مكونات الموجودات الفكرية وما يقابلها من أبعاد مقياس الأداء المتوازن. ويبين جوانب التكامل بين الموجودات الفكرية بمكوناته وكفاءة الأداء عبر إبعاد بطاقة الاداء المتوازن, فيما يأتي: (خلف,2014, ص

\section{أ - تكامل مؤشرات الأداء الأساسية:}

ينظر(Mouritsen) إلى مؤشرات الأداء على إنها أدوات بنائية , ومن ثم فإن هناك اختلاف بين مؤشرات الأداء المرتبطة بالموجودات الفكرية ومؤشرات الأداء المرتبطة ببطاقة الأداء المتوازن , وينبع هذا الاختلاف من طبيعة كل نوع من تنظيمات الأعمال , إذ إن 
مؤشرات الأداء المرتبطة بالموجودات الفكرية تنظر إلى تنظيم الأعمال على إنه نظام طبيعي , وتلعب دورا أساسيا في تبرير خطوات تنظيم الأعمال نحو دعم قدراته التأهيلية وتطويرها, في حين إن مؤشرات الأداء المرتبطة ببطاقة الأداء المتوازن تنظر إلى تنظيم الأعمال على إنه نظام ميكانيكي, وتلعب دورا أساسيا في دفع خطوات تنظيم الأعمال نحو دعم وتطوير قدراته التنافسية، ورغم هذه الاختلاف غير المؤثر في النظر إلى طبيعة مؤشرات الأداء الأساسية , إلا إنه هناك تكامل واضح بين مؤشرات الأداء لكل من الموجودات الفكرية و بطاقة الأداء المتوازن , لأن هذا التكامل بين الموجودات الفكرية و بطاقة الأداء المتوازن يعتمد على تكامل المؤشرات المالية والمؤشرات غير المالية لقياس مدى التقدم نحو تحقيق الأهداف الإستراتيجية الفرعية اللازمة لتفيذ إستراتيجية تنظيم الأعمال.

\section{ب- التكامل في اتجاه مسار العلاقتات الإرتباطية :}

كما تبين فإن مكونات الموجودات الفكرية تأخذ شكل علاقات ارتباطيه فيما بينها فإن كلا من رأس المال البشري يرتبط بعلاقة مع رأس المال الهيكلي وهذا يرتبط برأس المال الزبائني والتي تكاد تكون على الدرجة نفسها من الأهمية , ومن ثم فإن التنسيق بين هذه المكونات يأخذ شكل علاقات ارتباطيه جانبية , في حين إن مؤشرات الأداء عبر بعد بطاقة الاداء المتوازن تركز على تفاصيل إستراتيجية تنظيم الأعمال المتمثلة بيعد التعلم والنمو لتدريب وتطوير العاملين وكذلك بعد العمليات الداخلية الذي يركز على إنتاج المنتجات بجودة عالية وبعد الزبون الذي يركز على رضا الزبون وتحقيق رغباته ذلك لإنجاح عمل المؤسسة. \&ouritsen )

Larsen, 2005)

ث-التكامل الاستراتيجي:

يأتي التنافسية في التظيم الاعمال بصفة مبدئية من داخل الموجودات الفكرية, بمعنى إن اهتمام تنظيم الأعمال يجب إن ينصب على التطوير المستمر للقدرات التأهيلية وتدريب وتطوير العاملين وتنمية خبراتهم وذلك لرفع كفاءتهم الإنتاجية التي تمكن المؤسسة من الوصول إلى درجة معينة من التنافية , وعليه فإن الموجودات الفكرية تقوم على أساس إستراتيجية القدرات التأهيلية المستمدة من فلسفة نظرية المؤسسة القائمة على أساس الموارد أي إنه يجب إن تطور القدرات التأهيلية للعاملين وذلك لزيادة موارد المؤسسة من الداخل , أما من جانب بطاقة الأداء المتوازن فإن تنافسية تنظيم الأعمال تأتي بصفة مبدئية من الخارج , بمعنى إن اهتمام تنظيم الأعمال يجب إن ينصب على دعم العلاقات مع الزبائن من خلال تحقيق رضا الزبائن الحاليين وكسب زبائن جدد ويناء علاقة قوية معهم ؛ لإن الزبائن هم رأس مال المؤسسة الزبائني ومن خلاله يتم المحافظة على موقع المؤسسة التنافسي في الخارج , وعليه فإن مقياس الأداء المتوازن يقوم على أساس إستراتيجية تنافسية تتيح له السيطرة على السوق وتحقيق مركز تنافسي . Rivard \&)

Verreault, 2006,p) 


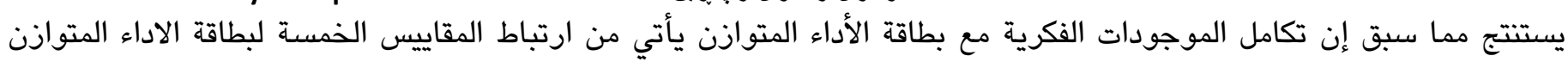
في سلسة من العلاقات السبية والأهداف الإستراتيجية التي تتكون من تمثيل متوازن بين المقاييس المالية وغير المالية وتتضمن هذه البطاقة مقاييس للمخرجات ومحركات للأداء حيث ترتبط معا في مجموعة من العلاقات السبية كما يمكن إن تكون هناك علاقة سبيية داخل البعد نفسه..Kaplan \& Norton, 2003, p407)

جاء وفقا لنموذج (Hilton)الذي يوضح الشكل (1) كيفية تحويل مناظير الأداء في بطاقة الأداء المتوازن من اداة اتصال مرئية إلى نموذج للتخطيط المالي لكي يستطيع كل المدراء في المستويات الدنيا من تقدير تأثير الربحية خلال تغيير نثاطاتهم في الشكل العام أو في عناصر هذا المقياس ـ والتكامل بين الموجودات الفكرية و مناظير بطاقة الاداء الاربعة وذلك لانها تبدأ ببعد التعلم والنمو الذي يمثل الموجودات البشرية و الذي يبين أن الزيادة في عدد ساعات التدريب سوف يؤدي الى رفع مستويات التعلم لدى العاملين ،و منظور العمليات الداخلية الذي يمثل الموجودات الهيكلية الذي يبين ان التخفيض في دورة الوقت سوف يؤدي الى تقليل نسبة التلف في الأنتاج ،و منظور الزبون الذي يمثل الموجودات الزبائنية والذي يبين ان السرعة في تسليم المنتج الى الزبون سوف تؤدي الى ارتفاع معدلات رضا الزبائن وتنتهي بالمنظور المالي الذي يكون نتيجة تكامل ابعاد مقياس الاداء ومكونات الموجودات الفكرية والذي يؤدي الى زيادة العائد من المبيعات وكما يأتي:

(1) (1) (1)

تكامل الموجودات الفكرية مع مناظير بطاقة الاداء المتوازن قياس الأداء المناظير الأداء
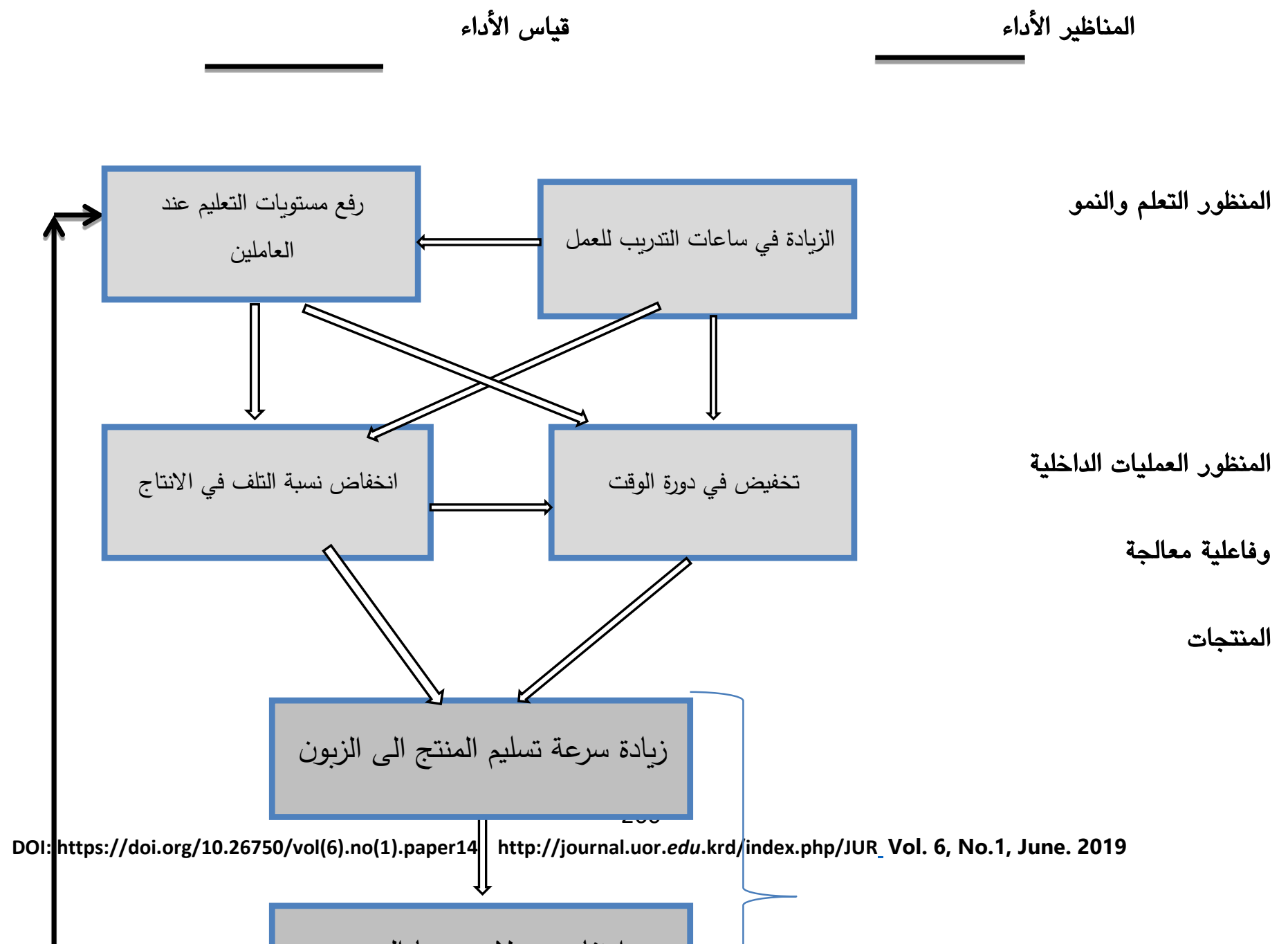
Source:Hilton, Ronald "Managerial Accounting", 4" ed Irwin McGraw-Hill company, 1999 :59

و يقترح الباحث اضافة المنظور الخامس فيما يتعلق بمنظور الاعتراف و القياس المحاسبي لكل المناظير الاخرى من خلال تحويل كل الانشطة و العمليات المناظير الاخرى الى ألارقام حقيقية بغرض اعترافها وقياسها وهي كالاتي:

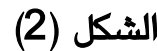

الشكل المقترح لتكامل الموجودات الفكرية مع مناظير بطاقة الاداء المتوازن

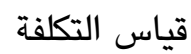

المناظير
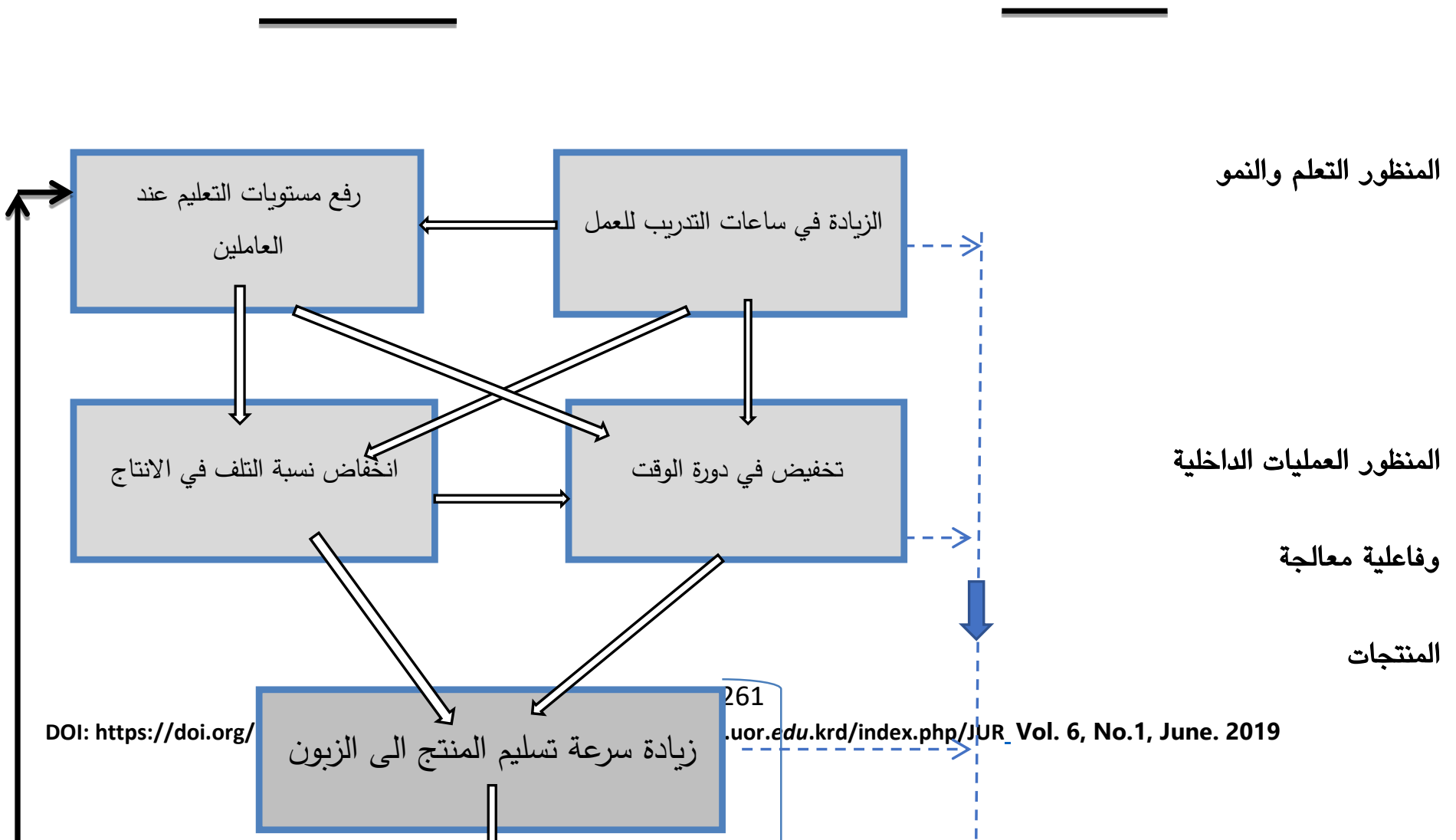


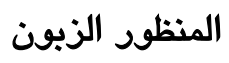

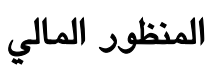

المنظور الاعتراف و القياس

2-قياس الموجودات الفكرية

نظرا لطبيعة الموجودات غير الملموسة التي تتكون منها الموجودات الفكرية ،فإن هناك صعوبات وقيود كثيرة تعترض عملية

القياس ،هذا فضلا عن التداخل في التأثير بين عناصر ومكونات الموجودات الفكرية مع المواد التظيمية الملموسة الأخرى ،ومن ثم يصعب عزل تأثير كل عنصر من العناصر على حدة .ويؤكد . (Guthrie \& Petty) على أهمية وضع وتحديد مؤشرات ومقاييس دقيقة لقياس الموجودات الفكرية ، وهذه المؤشرات تلزم المؤسسات الصغيرة ومتوسطة الحجم والكبيرة على حد سواء إذ إن تميز المؤسسات أصبح يعتمد بصورة كبيرة على فاعلية إدارتها لموجوداتها الفكرية .وتواجه الكثير من المؤسسات صعوبات حقيقية في قياس وتقويم الموجودات الفكرية ، خصوصا تلك المؤسسات التي تعتمد عاى مؤشرات كمية مادية في القياس، مثل قياس التكاليف والأرباح والمبيعات والحصة السوقية والموجودات المادية والالتزامات المالية وغيرها.(Betty R. \& Cuthrie J, 2000) ووفقا لما يرى (Chen, Zhu) فإن هناك أهمية كبيرة لقياس الموجودات الفكرية، وهذه الأهمية تتجسد من خلال الفرق بين الاساليب المحاسبية التقليدية والاساليب الحديثة لقياس الموجودات الفكرية وكما يأتي: (zhu \& Xie, 2004)

$$
\text { جدول (1) }
$$

الفرق بين الاساليب التقليدية والاساليب الحديثة

\begin{tabular}{|c|c|}
\hline الاساليب الحديثة & الاسـاليب التقليدية \\
\hline 1أ جنتمد على قياس وتقدير قيمة الموجودات الفكرية التي تشكل & 1 1-تعتمد على قياس الموجودات الملموسة من واقع \\
\hline
\end{tabular}




\begin{tabular}{|c|c|}
\hline 2- قادرة على قياس مكونات الموجودات الفكرية مثل & 2-غير قادرة على قياس مكونات الموجودات \\
\hline 3-تركز على الحقائق غير المادية وعلى النوعية. & 3-تركز على الحقائق المادية والكميات فقط \\
\hline 4- تركز على خلق القيمة. & 4الحقيقية. \\
\hline 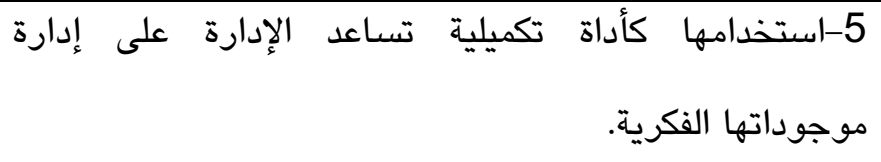 & 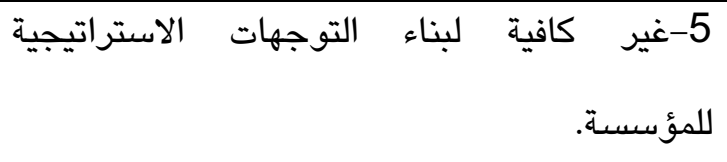 \\
\hline
\end{tabular}

المصدر: امينة ابراهيم خلف, قياس الأصول الفكرية وتقويمها بأستخدام بطاقة الأداء المتوازن, المعهد العالي للدراسات المحاسبية والمالية,2014.

المحور الثابث:

\section{اليات تطبيق بطاقة الأداء الهتوازن}

يتم التطرق هذا الفصل الى الية تطبيق بطاقة الأداء المتوازن في قياس رأس المال الفكري في جامعة رابرين لسنة(2017,2016,2015)وذلك من خلال مبحثين: الأول يقدم نبذة تعريفية عن جامعة رابرين, والثاني لتطبيق بطاقة الأداء المتوازن لقياس رأس المال الفكري في الجامعة.

\section{أ- نبذة تاريخية عن جامعة رابرين}

كانت نواة جامعة رابرين هي كلية العلوم الأنسانية التي تاسست في سنة (2005) في مدينة رانية و كلية التربية التي تأسست سنة (2004) في مدينة قلادزة و كانت من كليات جامعة (كويه) و هي جامعة الام لجامعة رابرين. جامعة رابرين هي إحدى الجامعات في اقليم كردستان العراق, التي تقع في مدينة رانية. تأسست في 8 تموز 2010 , وقد استبشر أبناء مدينة رانية بهذه الجامعة لما سيحققه هذا الصرح العلمي من آثار ايجابية على مجمل حياة المواطن في المدينة كونها ستسهم في تطوير الواقع الاجتماعي فيها من خلال فسح المجال أمام أبناء المدينة لإكمال دراستهم الجامعية, ودفع عجلة التطور والازدهار الاقتصادي والاجتماعي. وشهدت الجامعة منذ تأريخ تأسيسها مسيرة حافلة بالتطور والتوسع في كافة المجالات الفنية والعلمية و الإدارية و الخدمية من اجل افتتاح كليات جديدة إذ أصبح عدد الكليات الصباحية في عام (2017) (5) كلية فضلا عن بعض الأقسام العلمية المستقلة والتي يتكون من (3) اقسام. أما بالنسبة للدراسات المسائية في الكليات فقد شملت (3) كليات تمثلت بكلية العلوم الأنسانية, كلية التربية, كلية تربية الاساسية.

\section{ب- تطبيق بطاقة الأداء المتوازن لقياس رأس المال الفكري في جامعة رابرين.}


يهتم هذا المبحث بتطبيق بطاقة الأداء المتوازن ( balanced scordcard) في جامعة (رابرين) عينة البحث لقياس رأس المالها الفكري من اجل معرفة واقع الجامعة من خلال مجموعة من المؤشرات المالية وغير المالية, اذ قام الباحث بقياس رأسمال الفكرى للجامعة من خلال خمسة مناظير وكما يأتي:-

\section{1- 1 - منظور التفم والنمو.}

يهتم هذا المنظور بتنمية قدرات الموظفين داخل الجامعة من اجل بناء الجامعة وتطويرها لأجل طويل, وسيتم تطبيق هذا المنظور في الجامعة بالاعتماد على البيانات الفعلية التي حصلت عليها الباحث من مديرية البيانات و المعلومات و مديريات اخرى داخل الجامعة , وقد اختارت الباحث مجموعة من المؤشرات لتطبيق هذا المنظور في الجامعة وكما يأتي: أ-معدل دوران الموظفين:- يعد معدل دوران الموظفين مؤشرا مهما لمعرفة مدى كفاءة الجامعة وقدرتها على البقاء, حيث إن انخفاض هذا المعدل يدل على نجاح الجامعة في الاحتفاظ بموظفيها , ويمكن احتساب معدل دوران الموظفين كما يأتي:

$$
\text { جدول (1) معدل دوران الموظفين }
$$

\begin{tabular}{|c|c|c|c|}
\hline نسبة التغير & عدد الكلي للموظفين & عدد الموظفين الذين & العام الدراسي \\
\hline$\% 0.04$ & 511 & 2 & $2016-2015$ \\
\hline 0 & 518 & 0 & $2017-2016$ \\
\hline & & & \\
\hline
\end{tabular}

المصدر: اعداد الباحثان بالاعتماد على بيانات جامعة رابرين.

من خلال جدول الاعلى نلاحظ ان نسبة معدل الدوران الموظفين في كلا العامين هي نسبة قليلة جدا, و هذا يدل على كفائة الجامعة في الاحتفاظ بموظفيها.

\section{ب-أعداد التدريسيين حسب الشهادة العلمية.}

$$
\text { جدول (2) أعداد التدريسيين حسب الشهادة العلمية }
$$




\begin{tabular}{|c|c|c|c|c|}
\hline 210 & 2 & 157 & 51 & $2016-2015$ \\
\hline 218 & 2 & 167 & 49 & $2017-2016$ \\
\hline$\% 3.80$ & 0 & $\% 6.36$ & $\%(3.92)$ & \%نغير \\
\hline
\end{tabular}

المصدر: اعداد الباحثان بالاعتماد على بيانات جامعة رابرين.

ان هيئة التدرسين هم رأس المال الأهم للجامعة ومن خلال بيانات الجدول أعلاه نجد أن إجمالي عدد أعضاء الهيئة التدريسية في العام الدراسي (2015-2016) قد بلغ حوالي (210) عضو موزعين حسب الشهادة العلمية بنسبة (24\%) دكتوراه, و بنسبة (74\%) ماجستير, و بنسبة (2\%) دبلوم عالي, في حين بلغ إجمالي العدد التدريسيين (218) في العام الدراسي (2016-2017) التي ازدادة عن العام الدراسي السابق بنسبة (3.80\%), اما انخفض عدد التدريسيين من حملة شهادة الدكتوراه بنسبة(3.92\%) عن العام الدراسي السابق, و ازدادة حملة شهادة ماجستير بنسبة (6.36\%) عن العام الدراسي السابق, في حين ليس هناك اي تغير في حملة شهادة دبلوم العالي. سبب انخفاظ حملة شهادة دكتوراه تعود الى نقل منتسبين من حملة هذه الشهادة الى جامعات اخرى, حيث تحتسب انخفاظ في رأسمال الفكري للجامعة, و سبب ارتفاع في حملة شهادة ماجستير هي حصول على شهادة ماجستير من قبل منتسبي الجامعة و هذا يعني أزدياد قدرة الجامعة و ارتفاع في رأس المالها الفكري. ت- نسبة استقرار أعضاء الهيئة التدريسية. جدول(3) نسبة استقرار أعضاء الهيئة التدريسية.

\begin{tabular}{|c|c|c|c|}
\hline نسبة الاسقرار & العدد الكلي لأعضـاء & تركدا التدريسية الذين & العام الدراسي \\
\hline$\% 0.047$ & 210 & 1 & $2016-2015$ \\
\hline$\% 0.018$ & 218 & 4 & $2017-2016$ \\
\hline 0.029 & $\% 3.80$ & $\% 300$ & نسبة التغير \\
\hline
\end{tabular}

المصدر: اعداد الباحثان بالاعتماد على بيانات جامعة رابرين.

من خلال الجدول أعلاه نلاحظ أن نسبة الاستقرار لأعضاء الهيئة التدريسية في كلا العامين الدراسيين هي نسبة قليلة جدا, وهذا يدل على كفاءة وفاعلية الجامعة في الاحتفاظ بكادرها التدريسي, حيث كان اغلب التاركين للعمل في الجامعة هم من الذين تم نقلهم لجامعات أخرى حسب إرادتهم ورغبتهم في ذلك. 
جدول(4) عدد الدورات التدريبية للتدريسيين

\begin{tabular}{|c|c|c|c|c|}
\hline نسبة المشتركين & التمالي عدد & عدد المشاركين & عدد الدورات & عام الدراسي \\
\hline$\% 44$ & 210 & 92 & 3 & 2016-2015 \\
\hline$\% 47$ & 218 & 100 & 4 & $2017-2016$ \\
\hline$\% 3$ & $\% 3.80$ & $\% 9$ & $\% 33$ & نسبة التغير \\
\hline
\end{tabular}

المصدر: اعداد الباحثان بالاعتماد على بيانات جامعة رابرين.

و من خلال الجدول أعلاه نجد ان عدد الدورات التدرييية للتدريسيين بلغت (3) دورة في العام الدراسي (2015-2016) و بنسبة عدد المشتريكين (44\%) من اجمالي عدد التدريسين لنفس العام, في حين ازدادة عدد الدورات التدرييية في العام الدراسي (2016-2017) ليصل الى (4) دورة و بمعدل نمو (33\%) و بلغ عدد المشتركين في هذه الدورات للعام الدراسي (20162017) حوالي (47\%) من اجمالي عدد التدريسين لنفس العام و بمعدل نمو (9\%) مقارنة بالعام الدراسي السابق. بما تثير هذا على كفائة الجامعة في مجال توفير الدورات التدرييية لكادرها التدريسي.

2- عدد الكتب التي ألفها أعضاء الهيئة التدريسية وعدد الكتب المترجمة من قبلهم.

جدول(5) عدد الكتب المؤلفة من قبل أعضاء الهيئة التدريسية وعدد الكتب المترجمة

\begin{tabular}{|c|c|c|}
\hline الكتب المترجمة & الكتب المؤلفة & العام الدراسي \\
\hline 1 & 2 & $2016-2015$ \\
\hline 1 & 3 & 2017-2016 \\
\hline 0 & $\% 50$ & نسبة التغير \\
\hline
\end{tabular}

المصدر: اعداد الباحثان بالاعتماد على بيانات جامعة رابرين.

من خلال الجدول الاعلى نجد ان هناك (2) كتب مؤلفة من قبل الاعضاء الجامعة لسنة الدراسية (2015-2016) و(3) كتب مؤلفة لسنة الدراسية (2016-2017) التي ازدادة بمعدل (50\%) ـ اما بالنسبة لكتب المترجمة فهناك (1) كتب المترجمة لسنة الدراسية 
(2015-2016) و نفس العدد لسنة الدراسية (2016-2017) اي ليس هناك اي تطور في هذا المجال. و يعزو سبب عدم التطور

هذا الى علم توفر التخصيصات المالية اللازمة لذلك.

\section{2- 2 منظور المطيات الداخلية.}

يهتم هذا المنظور بالأنثطة والعمليات الداخلية التي يجب أن تهتم بها الجامعة والتي تمكنها من التميز وتحقيق أهدافها ومتطلبات زبائنها, وذلك من خلال الاستحداث والابتكار والتطوير في ضوء محددات المجتمع, وبصورة عامة فإن الأهداف الرئيسة لهذا المنظور هي تحسين وتطوير جودة العمليات الداخلية وتحسين الإنتاجية والإبداع, وسيتم تطبيق مؤشرات هذا المنظور في الجامعة (عينة البحث) وفق المؤشرات الآتية:

\section{أ-مؤشرات عملية التعليم, وتشمل:}

1- 1 الطاقة الاستيعابية للجامعة من الطلبة.

جدول (6) الطاقة الاستيعابية للجامعة من الطلبة

\begin{tabular}{|c|c|c|c|}
\hline الأجمالي الطاقة & 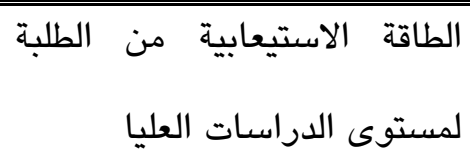 & الطاقة الاستيعابية من م الطلبة & العام الدراسي \\
\hline 680 & 50 & 630 & 2016-2015 \\
\hline 768 & 68 & 700 & $2017-2016$ \\
\hline$\% 13$ & $\% 36$ & $\% 11$ & نسبة التطور \\
\hline
\end{tabular}

المصدر: اعداد الباحثان بالاعتماد على بيانات جامعة رابرين.

و من خلال الجدول اعلاه نلاحظ ان هناك تطورا في الطاقة الاستعابية للجامعة علىمستوى الدراسات الأولية و العليا , حيث بلغ اجمالي الطاقة الاستعابية للجامعة من العام الدراسي (2016-2017) حوالي (768) طالبا و طالبة و بنسبة تطور(13\%) مقارنة بالعام الدراسي السابق, و هذا يدل على كفاءة الجامعة و تطورها في مجال استيعاب الطلبة.

2-عدد الرسائل والأطاريج الجامعية.

$$
\text { جدول(7) عدد الرسائل والاطاريح الجامعية }
$$

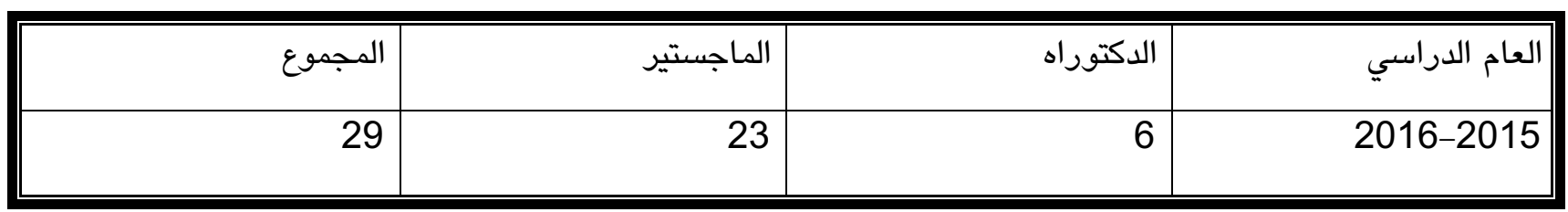




\begin{tabular}{|r|r|r|r|}
\hline 27 & 22 & 5 & $2017-2016$ \\
\hline$(\% 7)$ & $(\% 4.5)$ & $(\% 12.5)$ & \\
& & & \\
\hline
\end{tabular}

المصدر: اعداد الباحث بالاعتماد على بيانات جامعة رابرين.

و من خلال جدول اعلاه نلاحظ ان هناك انخفاض في عدد الاطاريح الدكتوراه بمعدل (12.5\%) في سنة الدراسية(2016-2017) مقارن بالعام الدراسي السابق, في حين هناك تراجع في عدد رسائل الماجستير بنسة انخفاظ (4.5\%) في العام الدراسي (20162017) مقارنة بلعام الدراسي السابق. ب-مؤشرات عملية البحث العلمي, وتشمل: 1-عدد المؤتمرات والندوات العلمية. جدول(8) عدد المؤتمرات والندوات العلمية

\begin{tabular}{|c|c|c|}
\hline عدد الندوات العلمية & عدد المؤتمرات العلمية & العام الدراسي \\
\hline 2 & 1 & $2016-2015$ \\
\hline 3 & 1 & 2017-2016 \\
\hline$\% 50$ & 0 & نسبة التغير \\
\hline
\end{tabular}

المصدر: اعداد الباحثان بالاعتماد على بيانات جامعة رابرين.

و من خلال جدول اعلاه نلاحظ ان ليس هناك اي تغير في عدد المؤتمرات مقارنة بين عامين الدراسيين, و حين هناك تغير في عدد الندوات العلمية في سنة الدراسية (2016-2017) و بنسبة (50\%) مقارنة بالعام الدراسي السابق, و سبب عدم امكانية الجامعة على ازدياد عدد المؤتمرات هي كساد في الضروف الأقتصادية التي حصلت في البلاد بين عامين (2014-2018). 2-عدد الانجازات في البحث العلمي.

$$
\text { جدول(9) عدد الانجازات في البحث العلمي }
$$

\begin{tabular}{|c|c|c|c|c|}
\hline مجموع & البحوث المنشورة في & البحوث المنشورة & المجلات المحكمة & العام الدراسي \\
\hline
\end{tabular}




\begin{tabular}{|c|c|c|c|c||}
\hline 107 & 5 & 102 & $2016-2015$ \\
\hline 105 & 7 & 98 & 4 & $2017-2016$ \\
\hline$\%(2)$ & $\% 40$ & $(\% 4)$ & 0 & 4 \\
\hline
\end{tabular}

المصدر: اعداد الباحثان بالاعتماد على بيانات جامعة رابرين.

و من خلال جدول اعلاه نلاحظ ان ليس هناك اي تغير في عدد المجلات المحكمة التي تصدرها الجامعة. في حين هناك انخفاض في عدد البحوث المنشورة بالنسبة (4\%) في العام الدراسي (2016-2017) مقارنة بالسنة السابقة. و هناك ازدياد في عدد البحوث المنشورة في المجلات الرصينة بمعدل (40\%) في العام الدراسي (2016-2017) مقارنة بلالعام الدراسي السابق.

\section{ج-مؤشرات عملية التدريب, وتشمل:}

1- عدد الاتفاقيات الثقافية الدولية المبرمة مع مؤسسات بحثية.

جدول(11) عدد الاتفاقيات الثقافية الدولية المبرمة مع مؤسسات العلمية

\begin{tabular}{|c|c|}
\hline (عدد الاتفاقيات المبرمة & \\
\hline 2 & $2016-2015$ \\
\hline 5 & $2017-2016$ \\
\hline \%150 & \\
\hline
\end{tabular}

المصدر: اعداد الباحثان بالاعتماد على بيانات جامعة رابرين.

من خلال جدول اعلاه نلاحظ ان هناك ازدياد كبير في عدد الاتفاقيات الدولية المبرمة مع مؤسسات العلمية بمعدل (150\%) في العام الدراسي (2016-2017) مقارنة بالعام الدراسي السابق. و يدل هذا على كفاءة الجامعة في الاتفاقيات المبرمة مع مؤسسات

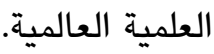

\section{3- منظور الزبائز ( الطلاب).}

يركز هذا المنظور على الطلبة باعتبارهم زبائن الجامعة والمستفيدين من خدماتها, وعلى الأنشطة التي تلبي احتياجاتهم وسيتم تطبيق هذا المنظور في جامعة رابرين عينة البحث بالاعتماد على البيانات الفعلية التي حصلت عليها الباحث من قسم التسجيل وشؤون الطلبة في الجامعة. وقد اختارت الباحث مجموعة من المؤشرات لتطبيق منظور الزبائن في جامعة رابرين وكما يأتي:

أ- أعداد الطلبة الموجودين فعلا حسب اللدراسة أولية وعليا.

جدول(12) أعداد الطلبة الموجودين فعلا حسب الدراسة أولية وعليا 


\begin{tabular}{|c|c|c|c|c|c|c|}
\hline المجموع & نسبة & طلبة الدراسـات & نسبة & طلبة الدراسات & طلبة الدراسـات & العام الدراسي \\
\hline 4419 & $\% 1.5$ & 61 & $\% 98.5$ & 390 & 3968 & $2016-2015$ \\
\hline 5560 & $\% 2$ & 99 & $\% 98$ & 1077 & 4384 & $2017-2016$ \\
\hline$\% 26$ & $\% 0.5$ & $\% 62.25$ & $\% 0.5$ & $\% 176$ & $\% 10.5$ & نسبة التغير \\
\hline
\end{tabular}

المصدر: اعداد الباحثان بالاعتماد على بيانات جامعة رابرين.

و من خلال جدول اعلاه نلاحظ أن اجمالي عدد الطلبة في العام الدراسي (2016-2017) قد بلغ حوالي (5560) طالبا و طالبة و بمعدل نمو قدره (26\%) عن العام الدراسي السابق. كما نلاحظ أن عدد طلبة الدراسات الأولية للعام الدراسي (2016-2017) قد بلغ (5461) طالبا و طالبة (دراسة الصباحية و المسائية) و بنسة (98 \%) من اجمالي عدد الطلبة لنفس العام, و بمعدل نمو قدره (10.5\%) بالنسبة للدراسات الصباحية و (176\%) بالنسبة للدراسات المسائية مقارنة بالعام الدراسي السابق, في حين بلغ اجمالي عدد طلبة الدراسات العليا للعام الدراسي (2016-2017) (99) طالبا و طالبة و بنسبة (2\%) من اجمالي عدد الطلبة لنفس العام, و بمعدل نمو قدره (62.25).

\section{ب- رضا الطلبة ( الزبوز) ).}

لقد تم تحليل أراء و استجابات الطلبة حول رضاهم لعملية التدريس و المدرسين في مختلف المجالات التدريسية و غير تدريسية و بحدود حوالي اغلية الطلاب وفق استبانة تم اعدادها من قبل ( مديرية جودة التعليم ). وقد تم استخدام لهذا الغرض مقياس (Likert) الخماسي الذي يتوزع من اعلى وزن الى أوطأ وزن له وتم اعطاء الدرجة (4-5) لتمثل حقل الاجابة (جيد جيدا ) و الدرجة (1-2) لتمثل حقل الاجابة (رديء) و بينما درجتان (2-3, 3-4) لتمثل حقول الاجابة ( متوسط, جيد) على التوالي. و قد تم استخدام الوصفي و التحليلي, و استخرجت التوزيعات التكرارية و الاوساط الموزونة لكل الكليات الجامعة يتم على ضوئها تحديد مستوى رضا الطلبة و كما موضح في أدناه.

1- بالنسبة لكلية العلوم الانسانية التي ساهمت حوالي (989) الطلاب في الاجابة على لاستبانة و تبين ان معدل الوسيط

لاستجابات الطلبة هي درجة (3.6) (جيد ). و يدل هذا على رضا الطلبة على التدريسين و عملية التدريس في الجامعة, 2- و بالنسبة لكلية التربية الاساسية التي ساهمت حوالي (1421) الطلاب في الاجابة على لاستبانة و تبين ان معدل الوسيط

لاستجابات الطلبة هي درجة (3.9) (جيد ). و يدل هذا على رضا الطلبة على التدريسين و عملية التدريس في الجامعة. 3- و بالنسبة لكلية التربية التي ساهمت حوالي (852) الطلاب في الاجابة على لاستبانة و تبين ان معدل الوسيط لاستجابات الطلبة هي درجة (3.4) (جيد ). و يدل هذا على رضا الطلبة على التدريسين و عملية التدريس في الجامعة. 
4- و بالنسبة لكلية العلوم التي ساهمت حوالي (581) الطلاب في الاجابة على لاستبانة و تبين ان معدل الوسيط لاستجابات

الطلبة هي درجة (3.2) (جيد ). و يدل هذا على رضا الطلبة على التدريسين و عملية التدريس في الجامعة.

5- و بالنسبة لكلية التمريض التي ساهمت حوالي (278) الطلاب في الاجابة على لاستبانة و تبين ان معدل الوسيط لاستجابات

الطلبة هي درجة (3.5) (جيد ). و يدل هذا على رضا الطلبة على التدريسين و عملية التدريس في الجامعة.

6- و بالنسبة لقسم الثروة الحيوانية التي ساهمت حوالي (98) الطلاب في الاجابة على لاستبانة و تبين ان معدل الوسيط

لاستجابات الطلبة هي درجة (3.1) (جيد ). و يدل هذا على رضا الطلبة على التدريسين و عملية التدريس في الجامعة. 7- و بالنسبة لقسم المحاصيل النباتية التي ساهمت حوالي (32) الطلاب في الاجابة على لاستبانة و تبين ان معدل الوسيط

لاستجابات الطلبة هي درجة (3.8) (جيد ). و يدل هذا على رضا الطلبة على التدريسين و عملية التدريس في الجامعة. 8- و بالنسبة لقسم الهنسة المدنية التي ساهمت حوالي (68) الطلاب في الاجابة على لاستبانة و تبين ان معدل الوسيط

لاستجابات الطلبة هي درجة (3.3) (جيد ). و يدل هذا على رضا الطلبة على التدريسين و عملية التدريس في الجامعة. 9- لذلك وبشكل عام وفيما يتعلق بمنظور الزبائن( الطلبة ) يتبين أن هناك تطورا في عدد الطلبة الموجودين فعلا و تطورا في عدد الطلبة المتخرجين ,وان هناك مستوى رضا جيد من قبل الطلبة حول الكلية والقسم العلمي في مختلف المجالات و التي بلغ حوالي ( 3.47) مما يدل على رضا الطلبة عن الخدمات المقدمة من قبل الجامعة.

4-المنظور المالئ.

يعد المنظور المالي من المناظير المهمة في بطاقة الأداء المتوازن إذ يصف هذا المنظور النتائج الملموسة للاستراتيجية من الناحية المالية التقليدية وتمثل نتائجه مقاييس موجهة نحو تحقيق الأهداف المالية, ويوجد العديد من المؤشرات المستخدمة لقياس المنظور المالي, ولكن اختارت الباحث أهم المؤشرات المتاحة للاستخدام وفقا لما موجود في ميدان التطبيق وذلك بالاعتماد على البيانات التي حصلت عليها من قسم الشؤون المالية في الجامعة, وسيتم تطبيق المنظور المالي في الجامعة على وفق المؤشرات الآتية:

\section{أ-نسبة المصروفات الفملية لحساب الرواتب إلى التخصيصات المالية لحساب الرواتب:-}

ان المصروفات لحساب الرواتب هي مستحقات التي يجب على المؤسسة ان تدفعها و تظهر التزام المؤسسة مع منتسيبها و كانت بيانات نسبة إجمالي المصروفات الفعلية لحساب الرواتب إلى التخصيصات المالية لحساب الرواتب والتي تثمل (رواتب الموظفين, مكافآت تثجيعية للعاملين, أجور متعاقدين, أجور محاضرات, أجور امتحانات, أجور لجان, المجازين دراسيا, مخصصات خطورة, الأعمال الإضافية, مخصصات استثنائية, مخصصات منصب, خدمه جامعية, مخصصات لقب علمي, مخصصات جغرافية, مخصصات زوجية,مخصصات أولاد, مخصصات شهادة, مساهمة التقاعد الحكومي) بالشكل الآتي: جدول (13) الرواتب كنسبة من التخصيصات 


\begin{tabular}{|c|c|c|c|c|}
\hline التغير & 2016 & 2015 & *2013 & البيان \\
\hline 0 & $4,230,000,000$ & $4,230,000,000$ & $4,230,000,000$ & مجموع الرواتب \\
\hline$\% 6, \% 14$ & $10,280,645,900$ & $9,698,095,150$ & $8,534,235,600$ & مجموع الرواتب \\
\hline$\% 14, \% 27$ & $\% 243$ & $\% 229$ & $\% 202$ & المبالغ الفعلية/المبالغ \\
\hline
\end{tabular}

*نظرا لظروف الاقتصادي التي حصلت في البلاد ليست هناك اي تخصيصات المالية لسنة (2017,2016,2015,2014), لذا ناخذ سنة (2013) كسنة اساسية لغرض المقارنات.

من خلال جدول اعلاه نلاحظ ان نسبة الصرف لحساب الرواتب هي اكثر من ضعف للتخصيصات المالية لحساب الرواتب, حيث بلغت نسبة الصرف (229\%) لسنة (2015), و ارتفعت هذا النسبة الى (243\%) من اجمالي التخصيصات المالية لسنة (2016). و هذا يدل على عدم التزام الجامعة بالمبالغ المخصصة لحساب الرواتب. نسبة من هذه التجاوزات هي نتيجة ازدياد في عدد التعينات للمنتسبين الجامعة.

\section{5- 5نظور الأعتراف و قياس رأس المال الفكري:_}

من الممكن الاعتراف و القياس المحاسبي الفعلي لكل المناظير الاخرى من خلال تحويل كل النثاطات و العمليات الى الارقام حقيقية و ايجاد حلول محاسبة لقياس و اعتراف المحاسبي لرأس المال الفكري استنادا الى المعيار الدولي المرقم (38) المخصص للموجودات

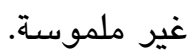

ان المنظور الاعتراف و قياس المحاسبي لرأس المال الفكري هي اهم المنظور التي تظهر فيها جميع المبالغ التي تصرف لتكوين و تطوير رأس المال الفكري للجامعة, و البيانات على الاثكال التالية:-

\section{أ- القياس المحاسبي لرأس المال الفكري}

\section{1-مؤشر صرف مخصصات لأعضاء هيئة التدريسية.}

استعان الباحث بالراتب اسمي و مخصصات الشهادة و مخصصات الخدمة الجامعية والمخصصات لقب علمي و مخصصات التشيع في عملية قياس رأس المال الفكري في عينة البحث ، إذ تم الاعتماد عليها بصورة أساسية وذلك بسبب الطبيعية المعنوية 

والفكرية لتلك المخصصات ، كما أن التدريسين الذين يحصلون على تلك المخصصات يمتلكون خبرة ومعرفة وظيفية كافية تؤهلهم بان يتم اعتبارىم جزءا أساسيا من موجودات الجامعة كباقي الموجودات الأخرى ، ولذلك تمت عملية القياس وفق الجداول الآتية-: تظهر في هذا المؤشر اغليية المستحقات التي تدفع للتدرسين مقابل خدمات التي تقدم الى الجامعة و الزبائن و التي يتكون من ( راتب أسمي, مخصصات الشهادة, مخصصات تفرغ الجامعي, مخصصات لقب علمي, مخصصات التشجيع). جدول رقم (14) قياس مستحقات من المخصصات لأعضاء هية التدريسية. ( المبالغ بالدينار)

\begin{tabular}{|c|c|c|c|c|c|}
\hline مجموع & مخصصات & مخصصات لقب & مخصصات تفرغ & مخصصات شهادة & البيان \\
\hline 2473092000 & 393600000 & 188815800 & 989152800 & 901523400 & 2015 \\
\hline 3086458200 & 626559600 & 233611800 & 1177679400 & 1048607400 & 2016 \\
\hline$\% 25$ & $\% 59$ & $\% 24$ & $\% 19$ & $\% 16$ & نسبة التغير \\
\hline
\end{tabular}

المصدر: اعداد الباحثان باعتماد على بيانات الجامعة.

من خلال جدول اعلاه يتبين ان بعض المبالغ التي تصرف كمستحقات للتدريسين في سنة (2015) هي (2473092000) دينار كمجموع, في حين ازدادة هذا المبلغ بنسبة (20.5\%) في سنة (2016) لتصل الى (3086458200) دينار كمجموع • و هذا الارتفاع هي تتيجة ازدياد عدد التدريسين و الحصول الترقيات العلمية من قبل التدريسيين.و المبالغ هي مبالغ السنوية التي تصنف كمصروفات رأسمالية تحمل على قائمة الميزانية العمومية. 2_ـمؤشر كلفة اللدورات التدريبة للتدريسين.

تظهر في هذا المؤشر جميع المبالغ التي تصرف للدورات مثل (المحاضرات, المستلزمات), و تظهر ايضا ايرادات على الدورة مثل (حق اشتراك في الدورة). والتي هي على شكل التالي.

جدول رقم (15) كلفة و ايرادات الدورات. ( المبالغ بالدينار)

\begin{tabular}{|c|c|c|c|}
\hline ايرادات الدورات & كلفة الدورات & عدد الدورات & البيان \\
\hline 9560000 & 3680000 & 3 & 2016-2015 \\
\hline 10000000 & 3950000 & 4 & $2017-2016$ \\
\hline$\% 4.5$ & $\% 7$ & $\% 33$ & نسبة التغير \\
\hline
\end{tabular}

المصدر: اعداد الباحثان باعتماد على بيانات الجامعة. 
كما تبين في جدول اعلاه في سنة دراسية (2015-2016) افتتحت الجامعة (3) دورات( دورة طرق تدريس و دورتين لللغة النجليزية) للتدريسين ,والمبالغ التي تصرف للمحاضرين و المستلزمات الدورات هي مبلغ (3680000) دينار في حين ايرادات الدورة هي (9560000) دينار, حيث مبلغ (9000000) دينار هي ايراد دورة طرق تدريس التي استلم من المشتركين التي عددهم بلغ (60) مشترك, والباقي هي ايرادات دورة اللغة الانجليزية. في حين ارتفع تكاليف الدورات في سنة دراسية (2016-2017) الى (3950000) دينار و التي هي (4) دورات. في حين ارتفع ايرادات الدورات لتصل الى (10000000) دينار, حيث مبلغ (9000000) دينار هي ايرادات دورة طرق تدريس و الباقي هي ايرادات الدورات اخرى. كذلك تعتبر هذه المبالغ مصروفات رأسمالية تضاف الى الرواتب والمخصصاتات والتي سيتم اعتبارها لاحقا رأس مال الفكري.

3مؤشر كلفة الرسائل و الاطاريج الجامعية.

تظهر في هذا المؤشر المبالغ التي تصرف للطلاب الدراسات العليا (دكتوراه,ماجستير) لطبع و تعضيد اطاريح و رسائلهم, و التي هي على شكل التالي:-

جدول رقم (16) كلفة الرسائل و الاطاريح. ( المبالغ بالدينار)

\begin{tabular}{|c|c|c|c|}
\hline 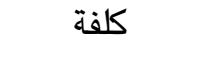 & عدد رسـائل ماجستير & عدد اطاريح دكتوراه & 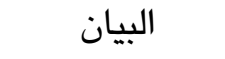 \\
\hline 36000000 & 23 & 6 & $2016-2015$ \\
\hline 39250000 & 22 & 5 & $2017-2016$ \\
\hline$\% 9$ & $(\% 4)$ & $(\% 20)$ & نسبة التفير \\
\hline
\end{tabular}

المصدر: اعداد الباحثان باعتماد على بيانات الجامعة.

كما تبين من خلال جدول اعلاه نلاحظ ان في سنة دراسية (2015-2016) مبلغ التي تصرف لطبع و تعضيد الاطاريح و الرسائل هي مبلغ (36000000) دينار و كذلك تعتبر هذه المبالغ مصروفات رأسمالية تضاف الى المصروفات الاخرى والتي سيتم اعتبارها لاحقا رأس مال الفكري. و يلاحظ ان هذه المبالغ سيتم اعتبارىا موجود يحمل على قائمة الميزانية العمومية في نهاية السنة المالية ويحذف هذه المبالغ من قائمة الأرباح والخسائر.

\section{4_مؤشر كلقة المؤتمرات و الندوات العلمية.}

تظهر في هذا المؤشر المبالغ التي تصرف للمؤتمرات و الندوات العلمية التي قام بها الجامعة والتي هي على شكل التالي. جدول رقم (17) كلفة المؤتمرات و الندوات. ( المبالغ بالدينار) 


\begin{tabular}{|r|r|r|r|}
\hline 14506000 & 2 & 1 & $2016-2015$ \\
\hline 17425000 & 3 & 1 & $2017-2016$ \\
\hline$\% 20$ & $\% 50$ & 0 & (ن) \\
\hline
\end{tabular}

المصدر: اعداد الباحثان باعتماد على بيانات الجامعة.

من خلال جدول اعلاه يتبين ان في سنة الدراسية (2015-2016) صرف الجامعة مبلغ (13750000) دينار للمؤتمر العلمي التي قام بها الجامعة, و ندوتين بتكلفة (435000,321000) دينار. اما في سنة دراسية (2016-2017) صرف الجامعة مبلغ (16350000) دينار كتكلفة المؤتمر العلمي و ايضا صرف مبالغ (410000,280000,385000) لثلاث ندوات علمية. هذا المبالغ نعتبر كقيمة لرأس المال الفكري في الجامعة والتي سيتم اعتبارها موجود يحمل على قائمة الميزانية العمومية في نهاية السنة المالية ويحذف ذلك المبلغ من قائمة الأرباح والخسائر.

\section{5_كلفة الانجازات في البحث العلمي.}

تظهر في هذا المؤشر جميع المبالغ التي تصرف الجامعة للمجلات العلمية و البحوث مثل ( حق الطبع , مكافأت للمقييم العلمي للبحوث, حق نشر في المجلات العالمية) والتي هي على شكل التالي.

جدول رقم (18) كلفة الانجازات في البحث العلمي. ( المبالغ بالدينار)

\begin{tabular}{|c|c|c|c|c|c|}
\hline مجموع الكلف & كلفة البحوث & البحوث & كلفة المجلات & المجلات & البيان \\
\hline 35220000 & 4420000 & 5 & 30800000 & 4 & $2016-2015$ \\
\hline 13050000 & 5150000 & 7 & 7900000 & 4 & $2017-2016$ \\
\hline$(\% 170)$ & $\% 16.5$ & $\% 40$ & $(\% 290)$ & 0 & نسبة التفير \\
\hline
\end{tabular}

المصدر: اعداد الباحثان باعتماد على بيانات الجامعة.

من خلال جدولاعلاه يتبين ان في سنة دراسية (2015-2016) اصدرت الجامعة (4) عدد من المجلات العلمية بكلفة (30800000) دينار والتي هي كلفة الطبع و تعضيد و مكافأت المقومين العلمين للبحوث, و صرفت الجامعة مبلغ (4420000) دينار كحق نشر ابحوث رصينة في المجلات العالمية, اما في سنة دراسية (2016-2017) صرفت الجامعة مبلغ (7900000) دينار والتي هي مكافأت للمقومين العلمين للبحوث و ليست هناك اي كلفة لطبع و تعضيد المجلات لأنه نشرت المجلات بشكل الكتروني في سايت الجامعة. و من الممكن ان نعتبر هذا المبالغ كقيمة لرأس المال الفكري في الجامعة والتي سيتم اعتبارىا موجود يحمل على قائمة الميزانية العمومية في نهاية السنة المالية ويحذف ذلك المبلغ من قائمة الأرباح والخسائر. 
تظهر في هذا المؤشر جميع المبالغ التي تدفع الجامعة مقابل الاتفاقيات العلمية مع المؤسسات العلمية العالمية والتي هي على شكل التالي.

جدول رقم (19) كلفة الاتفاقيات الثقافية المبرمة. ( المبالغ بالدينار)

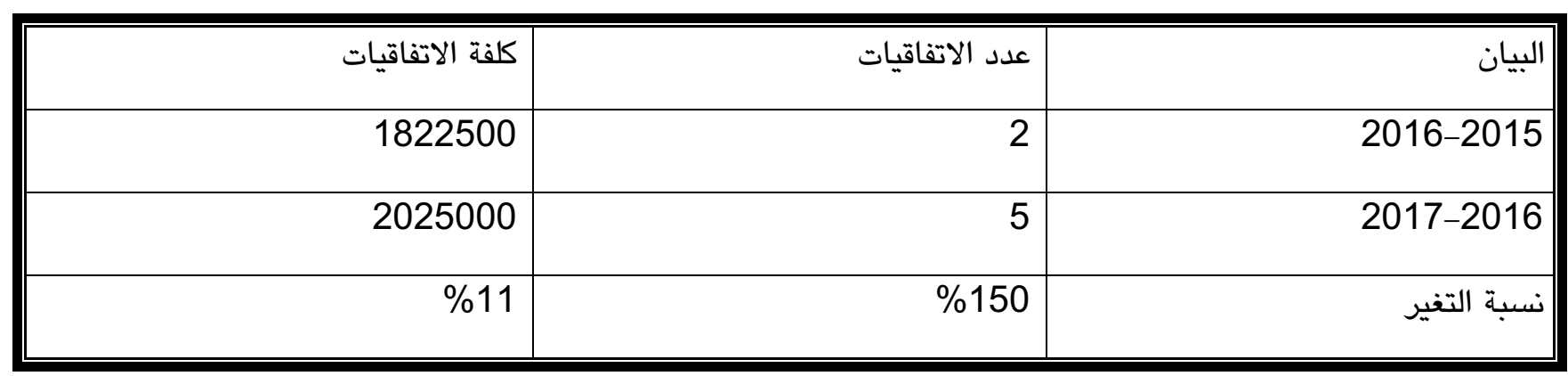

المصدر: اعداد الباحثان باعتماد على بيانات الجامعة.

من خلال جدول اعلاه يتبين ان في سنة دراسية (2015-2016) تم توقيع على (2) اتفاقية علمية من قبل الجامعة مع المؤسسات العلمية العالمية, واحد من الاتفاقيات يتكلف على الجامعة مبلغ (1822500) دينار كحق الاتفاقية, و لاكن الاتفاقية الثانية لا يتكلف الجامعة اي مبالغ. اما في سنة دراسية (2016-2017) تم توقيع (5) اتفاقيات علمية مع المؤسسات العلمية العالمية, واحد من الاتفاقيات يتكلف على الجامعة مبلغ (2025000) دينار,اما الاتفاقيات الاخرى لا يتكلف اي مبلغ على الجامعة. و من الممكن ان نعتبر هذا المبالغ كقيمة لرأس المال الفكري في الجامعة والتي سيتم اعتبارىا موجود يحمل على قائمة الميزانية العمومية في نهاية السنة المالية ويحذف ذلك المبلغ من قائمة الأرباح والخسائر. جدول (20) جميع التكاليف لرأس المال الفكري

\begin{tabular}{|c|c|c|}
\hline 2016 & 2015 & البانات \\
\hline الكلفة الكلة & الكلفة الكلة & \\
\hline 3086458200 & 2473092000 & مخصصات لأعضاء هيئة \\
\hline 3950000 & 3680000 & الدورات التدريبة للتدريسين \\
\hline 39250000 & 36000000 & الرسائل و الاطاريح الجامعية \\
\hline 17425000 & 14506000 & المؤتمرات و الندوات العلمية \\
\hline 13050000 & 35220000 & ات في البحث العلمي \\
\hline
\end{tabular}




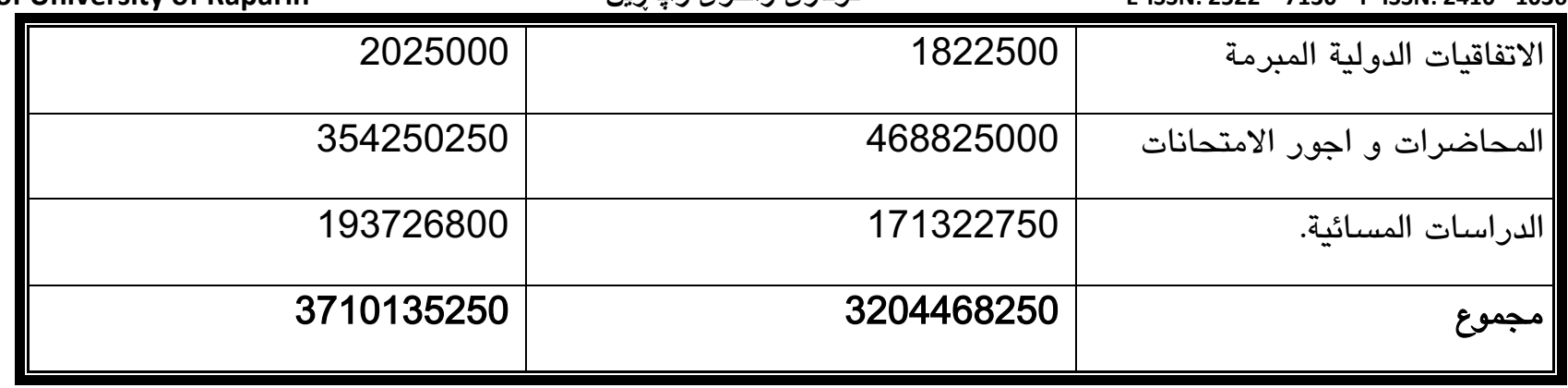

المصدر: اعداد الباحثان باعتماد على بيانات الجامعة.

ومن خلال جدول اعلاه يمكن ان نحدد كلفة رأس المال الفكري للجامعة في الجامعة, في سنة (2015) كلفة رأس المال الفكري كانت (3204468250) دينار. في حين ارتفعت التكاليف في سنة (2016) الى (3710135250).

يتبين من لشكل رقم (1) (التكامل الموجودات الفكرية مع مناظير بطاقة الاداء المتوازن) و وفقا للنتيجة التي توصلنا اليه من قياس رأس المال الفكري, يمكن ان نوضح هذا التكامل بشكل اتي:وفقا لمنظور التعلم و النمو التي يهتم بتطوير قدرة المنتسيين من خلال افتتاح الدورات العلمية و التعليمية لغرض ارتفاع قدرتهم العلمية و التي يؤدي الى تطوير مهاراتهم في عملية الانتاج (منظور العمليات الداخلية) و ازدياد عملية الانتاج (نسبة الخريجين) و تخفيض نسبة التلف (تخفيض نسبة الرسوب) و التي يؤدي الى انتاج المنتج في وقتها اي دون تأخير (التخرج دون تأخير). (منظور الزبائن) و من نتيجة الخدمات التي يتقدم المؤسسة(الجامعة) الى زبائنها (الطلاب) تؤدي الى ارتفاع رضا الزبون بنسة جيدا, (منظور المالي) و من نتيجة كل الخطوات الاعلى و نتيجة النجاح المؤسسة في تقديم الخدمات و التي يؤدي الى جذب نسبة كبيرة من الزبائن و هذا يعني ازدياد في عملية الانتاج و ارتفاع نسبة الايرادات.

كما هو معروف لم يكن الاعتراف بالموجودات الثابتة في المحاسبة الحكومية و لكن عند ايجاد معالجة محاسبة للموجودات الثابتة في المؤسسات الحكومية ادرجت ضمن الحسابات النظامية, و من الممكن وضع حسابات الموجودات الثابتة في دليل الحسابات الحكومية, حيث دليل الحسابات هو الإطار العام الذي يحتوى علي جميع أنواع الحسابات المعبرة عن العمليات المالية، ويتم تصنيفها في مجموعات متجانسة, و معالجتها ضمن الحسابات النظامية المدنية حيث يستخدم هذه المجموعة لمعالجة بعض الحسابات التي يكون استخدامها بصورة مزدوجة حيث ترد ضمن مجموعة حسابات النتجة و لا تتضمن حركة نقدية و تستخدم لضمان الرقابة و توفير البيانات. و يمكن عرض دليل حسابات الحكومة التي تنقسم إلى:

أـ- حسابات الموازنة: وهي حسابات ألإيرادات والمصروفات والتي تتفرع بدورها إلى حسابات فرعية وتحليلية جزئية طبعا

$$
\text { للتقسيم النمطي للموازنة. }
$$

ب- حسابات خارج الموازنة: ويطلق عليها الحسابات الوسيطة أو حسابات التسوية، وهي تفتح لخدمة حساب الموازنة التي تعتبر محل الاهتمام الأول في النظام المحاسبي الحكومي، وتنقسم إلى أربع مجموعات فرعية هي: 
1- الحسابات المدينة، وتسمي حسابات العهد أو الحسابات الجارية المدينة تحت التسوية، وتعبر عن المبالغ التي في ذمة الغير

للحكومة كالمدينين في المحاسبة المالية.

2-حسابات الدائنة وتسمى الأمانات أو الحسابات الجارية الدائنة تحت التسوية، وهي تعبر عن المبالغ التي في ذمة الحكومة للغير، كالدائنين في المحاسبة المالية .

3- الحسابات الجارية العامة، وتعبر عن وسائل الدفع كالشيكات والحوالات وأوامر الدفع النقدية والجهات التي يتم التعامل معها بالصرف أو التحصيل كالبنك المركزي والبنوك الأخرى والصندوق والخزائن الفرعية.

4- الحسابات النظامية، وهي الحسابات التي تفتح بغرض متابعة مستحقات بالحساب الختامي في نهاية السنة كأحد حسابات الموازنة، مع بقاء مكونات هذه الإنفاق كموجودات ثابتة تستخدم في النشاط لسنوات عدة.

وبذلك يتضح أن مكان حسابات الموجودات الثابتة في دليل حسابات الحكومة وهو في المجموعة الرابعة (الحسابات النظامية). و لمعالجة الموجودات الثابتة و التي نصت في كتاب (الاصول النضرية و العملية للمحاسبة الحكومية مع التطبيقات في العراق) في صفحة (313) معالجة قيود الموجودات الثابتة, و التي كتب كما يلي:

يتم معالجة المبالغ التي تصرف لشراء الموجودات الثابتة و كذلك مبالغ الموجودات الثابتة التي يتم الحصول عليها عن طريق اهداء من وحدة أخرى أو التبرع أو أي طريقة اخرى, حيث يتم تنظيم قيد لقيمة الموجودات الثابتة ( المدفوعة فعلاًَ أو مقدرة) و كما يلي:

\section{من ح / الموجودات الثابتة}

\section{الى ح / مقابل الموجودات الثابتة}

و عند بيع أو أهداء أو نقل أي من الموجودات الثابتة المثبت بها قيد كما في اعلاه, ينظم قيد بالقيمة الدفترية بـالفاء القيد اعلاه و كما يلي:من ح / مقابل الموجودات الثابتة

\section{الى ح / الموجودات الثابتة (السلوم 2000, ص 313)}

و وفقا للمعالجة المذكورة في اعلاه للموجودات الثابتة, و نأخذ بنظر الاعتبار بأن رأس المال الفكري هي جزء من الموجودات لكن هي موجود غير ملموس و من الممكن احتسابها ضمن موجودات أخرى.وكما مبين في ( دليل المالي و المحاسبي في العراق لسنة 2013) الموجودات أخرى ضمن باب الموجودات تحت دليل( 3-9-4-8), و اقترح حساب رأس المال الفكري ضمن الموجودات اخرى على مستوى الخماسي و على شكل (3-9-4-8-1), و التي من الممكن معالجتها على شكل التالي:- 
الى ح/ مقابل موجودات اخرى (4-9-4-8) ( دليل المالي و المحاسبي في العراق لسنة 2013,ص 161, ص 179) أو على شكل اوضح

من ح/ رأس المال الفكري (3-9-4-8-1)

الى ح/ مقابل رأس المال الفكري (4-9-4-8-1)

وبالتطبيق هذه المعالجة على بيانات عينة البحث ( جامعة رابرين) , يمكن معالجة رأس المال الفكري في قائمة المركز المالي وقتا للاتي: لسنة 2015

3204468250

3204468250 الى ح/ مقابل رأس المال الفكري

لسنة 2016

3710135250

3710135250 الى ح/ مقابل رأس المال الفكري

والتي تظهر في قائمة المركز المالي كما يأتي:-

شكل رقم (3)

كثف المركز المالي كما في 2016/12/31

\begin{tabular}{|c|c|c|c|c|c|c|}
\hline \multicolumn{2}{|c|}{ السنة 2016} & \multicolumn{2}{|c|}{ |السنة 2015} & \multirow{2}{*}{ اسم الحساب } & \multirow[t]{2}{*}{ 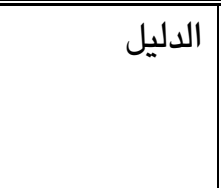 } & \multirow[t]{2}{*}{ الكثف } \\
\hline دينار & فلس & دينار & فلس & & & \\
\hline & & & & الموجودات & 3 & \\
\hline & & & & نقد في الصندوق & $1-1-3$ & \\
\hline & & & & السلف & $2-3$ & \\
\hline & & & & حسابات مدينة اخرى & $3-3$ & \\
\hline & & & & الحسـابات النظامية المدينة & 9 & \\
\hline & & & & موجودات اخرى & $8-4-9-3$ & \\
\hline 3710135250 & & 3204468250 & & رأس المال الفكري & $1-8-4-9-3$ & \\
\hline
\end{tabular}




\begin{tabular}{|c|c|c|c|c|}
\hline & & \multicolumn{3}{|c|}{ مجموع الموجودات } \\
\hline & & المطلوبات & 4 & \\
\hline & & الحسابات النقدية الدائنة & $1-4$ & \\
\hline & & حسابات الامانات & $2-4$ & \\
\hline & & حسابات دائنة اخرى & $3-4$ & \\
\hline & & مقابل موجودات اخرى & 8-4-9-4 & \\
\hline \multirow[t]{2}{*}{3710135250} & 3204468250 & مقابل رأس المال الفكري & 1-8-4-9-4 & \\
\hline & & \multicolumn{3}{|c|}{ مجموع المطلوبات } \\
\hline
\end{tabular}

بعد اعتراف بالرأس المال الفكري و قياسها يجب احتساب كيفية اطفاء كلفة رأس المال الفكري بأعتباره احد الموجودات غير الملموسة, و ذكر هذه المعالجة في معيار المحاسبة الدولي رقم (38) التي ينص, وجوب إطفاء موجود غير ملموس بشكل منتظم على أفضل تقدير لعمره النافع، وهناك افتراض قابل للدحض أن العمر النافع لموجود غير ملموس لن يزيد عن عشرين سنة عندما يتوفر الموجود للاستعمال، ولا يسمح معيار المحاسبة الدولي الثامن والثلاثون بان تقوم المؤسسة بتحديد عمر إنتاجي غير محدود لموجود غير ملموس، ويجب أن يبدأ الإطفاء عندما يتوفر الموجود للاستعمال . في حالات نادرة قد تتوفر أدلة مقنعة على أن العمر النافع لموجود غير ملموس سيكون لفترة محددة تزيد عن عشرين سنة، وفي هذه الحالات يتطلب معيار المحاسبة الدولي أن تقوم المؤسسة بما يلي: 1- إطفاء الموجود غير الملموس على أفضل تقدير لعمره الإنتاجي. 2- تقدير المبلخ القابل للاسترداد للموجود غير الملموس على الأقل سنويا لتحديد ما إذا كانت هناك أية خسارة في انخفاض القيمة. 3- الإفصاح عن أسباب دحض افتراض عدم زيادة العمر النافع لموجود غير ملموس عن عشرين سنة والعامل (العوامل ) التي

$$
\text { لعبت دورا هاما في تحديد العمر النافع للموجود غير الملموس. }
$$

اما يتطلب معيار المحاسبة الدولي الثامن والثلاثون وجوب أن يظهر أسلوب الإطفاء المستخدم نمط استهلاك المؤسسة للمنافع الاقتصادية للموجود، و إذا لم يكن ممكنا تحديد ذلك النمط بثكل موثوق فانه يجب تبني أسلوب القسط الثابت، ويجب الاعتراف بمبلغ الإطفاء على انه مصروف إلا إذا سمح أو تطلب معيار محاسبي آخر أن يتم إدخاله ضمن المبلغ المسجل لموجود آخر. 
1-تمثل بطاقة الأداء المتوازن اسلوب حديث لمتابعة التقدم المحرز نحو بلوغ الأهداف الاستراتيجية ,فهي ليست مجرد أداة لقياس ,

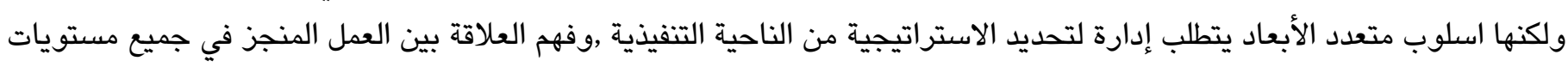
المؤسسة والأهداف الاستراتيجية. 2-إمكانية تطوير بطاقة الأداء المتوازن رمن خلال إضافة منظور أو أكثر لتتكامل مع المناظير الأصلية الأربعة ,وذلك حسب حاجة المؤسسة ويما يتلاءم مع تحقيق أهدافها الاستراتيجية. 3- رأس المال الفكري هو المحرك الأساسي لكافة الأعمال والأنشطة التي تقوم بها المؤسسة ، فضلا عن دوره في تحقيق أهدافها المتنوعة في زيادة طاقتها الإنتاجية وتحقيق الميزة التنافسية. 4-لا يوجد اتفاق بين المنظمات المحاسبية الدولية والمحلية على إصدار معيار دولي خاص برأس المال الفكري او الموارد البشرية يختص بقياسه والإفصاح عنه في القوائم المالية الختامية.

\section{ثانيا:الاستنتاجات الجانب العملي.}

1- من الممكن استخدام بطاقة الاداء المتوازن بمناظيرها الخمسة لقياس رأس المال الفكري في الجامعات من أجل تحديد قيمتها و اظهارها في القوائم المالية الختامية.

2- في ما يخص باستفلال التخصيصات المالية, تبين بأن نسبة المصروفات الفعلية اكثر من التخصيصات في اغلب السنوات. 3- تبين البحث الحالي بأن رغم لحداثة الجامعة ألا أن هناك جهود كبيرة من قبل ادارة الجامعة لتطوير الجامعة من حيث زيادة عدد الكوادر العلمية اللازمة و الاحتفاظ بهم و جذب كوادر جديدة وكفوءة حيث ان اغلب الكوادر العلمية الموجودة هم من خريجي الجامعات الخارجية. 4- تبين بأن هناك اهتمام من قبل الجامعة بأصدار عدد مناسب من المجلة العلمية في كل سنة و عقد الندوات والمؤتمرات العلمية و كذلك نثر بحوث علمية من قبل كوادرها في المجلات الداخلية و الخارجية.

5-من خلال التغذية الراجعة للطلاب( فيد باك) أظهرت ان رضا طلبة الجامعة بنسبة جيدة لتدريسيها و قد يرجع هذا الرضا لما تقدمه الجامعة من خدمات علمية لطلابها.

\section{ثالثا:التوصيات}

1-على ديوان الرقابة المالية السعي نحو تبني اسلوب بطاقة الاداء المتوازن في قياس رأس المال الفكري في الجامعات ونشر ثقافة استخدام بطاقة الأداء المتوازن. 
2- على المؤسسات الحكومية إيجاد الوسائل والإجراءات المناسبة التي تساعدها في تحقيق عملية القياس والإفصاح المحاسبي عن رأس المال الفكري في قوائمها المالية الختامية.

3-يتعين على المؤسسات الحكومية عدم تحميل كامل قيمة رأس المال الفكري على حساب النتيجة لأن رأس المال الفكري يعد من الموجودات المؤسسة وليس من مصاريفيا.

4- يوصي الباحث المؤسسات الحكومية بأن تدرك أهمية رأس المال الفكري ودوره في زيادة صافي الموجودات المؤسسة ، والذي يستوجب عليها الاهتمام به بصورة مستمرة كأحد الموجودات المعنوية مثلما هو الحال بالنسبة للموجودات الملموسة الأخرى 5- على الجامعة ان يحقق في الاتصال الفعال بين عناصر رأس المال الفكري التي سيتم قياس مخرجاتها. 6-يوصي الباحث الجهات الحكومية المعنية ان تنص قاعدة محاسبية محلية لقياس موجوداتها و عرضها على مجلس القواعد والمعايير المحاسبية العراقية لغرض دراستها وتعميمها للتطبيق.

المصادر

أولا: المراجع العربية. أ- الوثائق الرسمية:-

1- جامعة رابرين , سجلات و التقارير و القوائم المالية لسنة (2015,2016) 2- جامعة رابرين, بيانات و المعلومات المديريات و الاقسام الجامعة.

\section{ب-الرسائل الماجستير و الدكتوراه:-}

1- مريم شكري محمود نديم،تقييم الأداء المالي باستخدام بطاقة الأداء المتوا زن ,رسالة ماجستير،جامعة الشرق الأوسط، الأردن، 2013

2- التجانى عبدالله فرح ، المحاسبة عن رأس المال الفكرى ودورها فى تحديد جودة وفاعلية المعلومات المحاسبية ، رسالة ماجستير

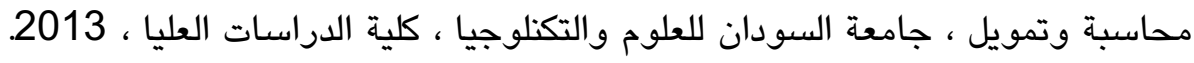

3- امينة ابراهيم خلف, قياس الأصول الفكرية وتقويمها بأستخدام بطاقة الأداء المتوازن, المعهد العالي للدراسات المحاسبية والمالية,2014.

4- علاء درويش , " ما هي القيمة المضافة في التسويق " رسالة ماجستير, جامعة دمشق - كلية الاقتصاد, 2010). ت-البحوث المنشورة في المجلات و الدوريسات.

1- توفيق عبد المحسن الخيال, 2005 ، أهمية المحاسبة عن رأس المال الفكري وتحديد آثاراها على جدوى المعلومات

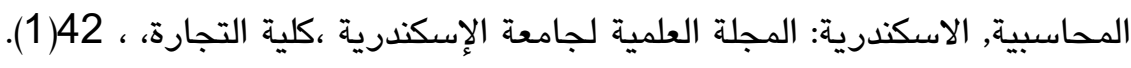
2- نهال احمد الجندي،2005، قياس وتقييم رأس المال الفكري ،احد المتطلبات الأساسية لتحديد قيمة المنثاه نموذج مقترح، مجلة

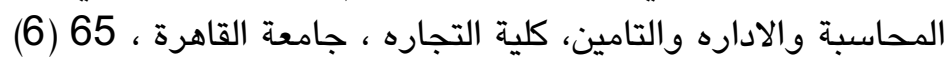

3- أيت مختار عمر, حمدى عمر،2011 ،( طرق و نماذج قياس رأس المال الفكرى) مداخله الى الملتقى الدولى الخامس حول: رأس المال الفكرى في منضمات الاعمال العربيه في ضل الاقتصاديات الحديثة، مدئر. 
4- أنعام محسن و نور حسن عبد الناصر, 2005، "أهمية ومدى استخدام بطاقة العلامات المتوازنة في تقوم الأداء,"

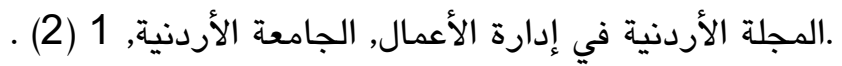

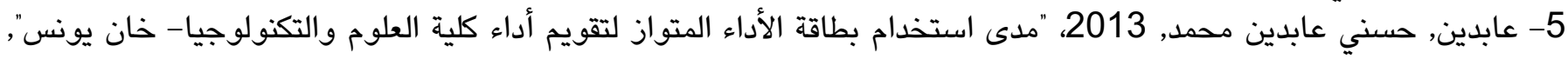
المؤتمر العلمي الأول"دور الكليات والجامعات في مئ تنمية المجتمع, فلسطين, قطاع غزةر.

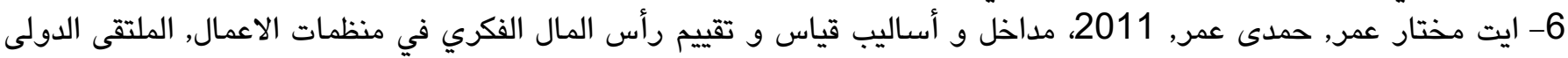
الخامس حول رأس المال الفكري.

7-سعود جايد مشكور,جعفر فالح ناصر 2013،" القياس و الافصاح المحاسبي عن راس المال البشري و دوره في زيادة قيمة

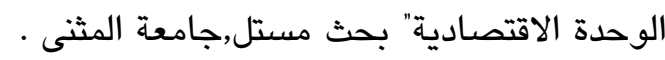

8- محمد عبد الحليم عمر, 1992، المعالجة المحاسبية للأصول الثابتة في المحاسبة الحكومية, نثر بالمجلة العلمية لكلية التجارة جامعة عين شمس. ث- الكتب.

1-محمد مطر, موسى السويطى, 2008، التأصيل النظرى للممارسات المهنية المحاسبة, دار وائل. 2-عبد الحميد عبد الفتاح المغربي،2009 ، بطاقة الأداء المتوازن (المدخل المعاصر لقياس الأداء الاستراتيجي) مصر ، المكتبة العصرية للنشر و التوزيع. 3- ريتشارد شرويد، وآخرون، 2006، "نظرية المحاسبة"، (ترجمة خالد علي أحمد كاجيجي)، الرياض، دار المريخ. 4- حسن عبدالكريم سلوم, الاصول النظرية و العملية للمحاسبة الحكومية مع التطبيقات لجمهورية العراق, الجامعة المستصرية, بدون ذكر السنة. 5-دليل المالي و المحاسبي في العراق,2013.

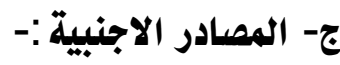

\section{A-Articls \& Theses}

1- Anderiessen , D, 2004،Intellecual Capitaluation and Measure Why and How , Intellecual Capitaluation pesearch Symposium Confreld School of Management October,.

2- Rivard, S., L. Raymond, \& D. Verreault, March 2006، "Resource - Based View and Competitive Strategy: An Integrated Model of the Contribution of IT to Firm Performance", the Journal of Strategic Information Systems, Vol. 15, Iss. 1,.

3- Kaplan, R.S. \& DP.Norton.(2004). " Measuring the Strategic Readiness of Intangible Assets " , Harvard Business Review, Vol. 82 , No. 1 .

4- Mouritsen, J., \& H.T. Larsen, 2005، "The 2nd Wave of Knowledge Management: The Management Control of Knowledge Resources through Intellectual Capital Information", Management Accounting Research, Vol. 16, Iss. 3.

5- Kaplan \& Norton, 2003, Balanced Scorecard. From strategy to action.

6- Betty R., \&Cuthrie,j.,(2000), Intellectual Capital.Liter ature Review Measurement, Reporting and Mangament,Journal of Intellectual Capital,1.(2). 
7-Chen, Jin, zhu, and Hong yaer xie. 2004 .measuring Intellectual capital: anew model and Empirical study "journal of Intellectual capital ..

\section{B-Books}

1-Campell , N.R. 1957 , Foundation of science, Dover publication,.

2- Hansen, Don R. \& Mowen, Maryanne M. 2006, Cost Management: Accounting

And Control, 5ed, America, Thomson South - Western,.

3- Stewart, T. (1997), Intellectual capital: The new wealth of organizations.

C-Accounting Standards Reports.

1-A.A.A "report of the committee on the foundations of accounting measurement" the acc Review. Supple to vol. XLIVI 1971.

\section{$\underline{\text { abstract }}$}

In recent years, the modern world has been making rapid progress in technological aspects due to the great role played by the human element in this progress as one of the productive factors contributing to the production process. In light of this, the current research aims to use one technique (Balanced Scorecard) to measuring the intellectual capital in the university and processing the accountant and show them in the financial statements. In order to reach the research objectives, the research relied on the data and information obtained by the researcher from the university. The descriptive and analytical approach was used for the purpose of collecting the data and the data into the search results. The results of the current research have shown that the Balanced Scorecard is a modern way to track progress towards strategic objectives, as it is not just a measuring tool but a multidimensional approach that requires management to define operational strategy and understand the relationship between work done at all levels of the organization and strategic objectives; The use of these tools for the purpose of measuring intellectual capital is the objective of the present research, intellectual capital is the main engine of all the activities and activities of the institution, as well as its role in achieving its various objectives in increasing its production capacity and achieving the advantage of competition Yes. The current research recommends that government institutions find the appropriate means and procedures to assist them in achieving accounting measurement and disclosure of 
intellectual capital in their final financial statements. Government institutions should not load the entire value of intellectual capital at the expense of the result because intellectual capital is an asset. The Foundation and not from the expenses.

Keywords: Intellectual capital, balanced scord card, measurement, descriptive and analytical regression.

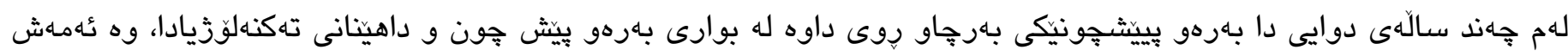

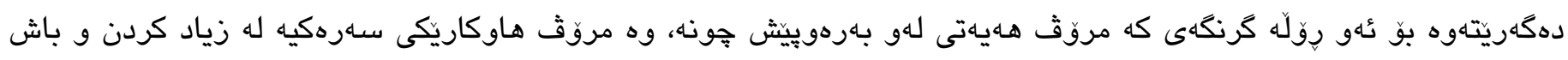
كردنى بهرهـ م. لهبهر رِّوشنايى ئهمه ،ئامانجى ئهم تويّزينهوهيه بريتيه له بهكار هينانى ئامرازى (كارتى ئهنجامدانى هاوسهنحى) به

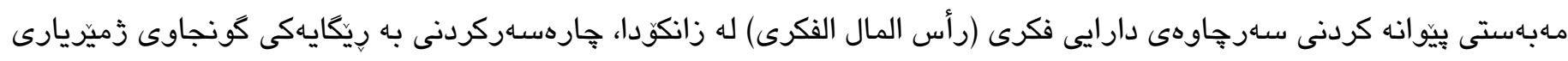
وه دهرخستنى له رايّورته داراييهكاندا. بوّ كَيشتن به ئامانجى تويّزينهوهكه، يشتمان بهستوه بهو داتاو زانيارييانهى كه دهستمان كهوتووه له زانكو. بوّشيكار كردن و كَهيشتن به ئامانجى تويّزينهوهكه بيردوزهى باسكردن و شيكاركردنمان بهكار هيناوه (المنهج

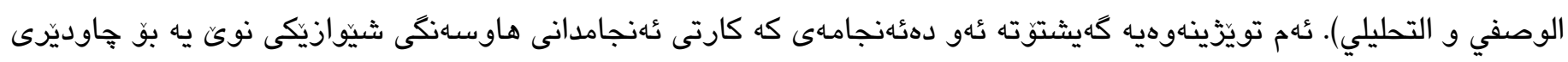
كردنى بهرهو يِيشِونى دامهزراوهكان بهرهو بهديهينانى ئامانجى ستراتيجى, وه ئهم كارته تهنها بريتى نيه له ئامرازيكّى بيّوانه

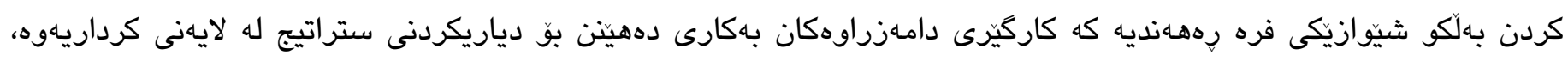
بهكار هينانى بو ليكّ تيكَهيثتن له نيوان كرداره جيّ بهحي كراوهكان و عامانجه ستراتيجيهكان، بهكار هينانى ئهم كارته بهمهبهاستى بيوانهردنى سهرجاوهى فكرى دارايى ئامانجى ئهم تويَّينهوهيه. سهرجاوهى فكرى دارايى بزوينهرى سهرهكيه بو كُشت

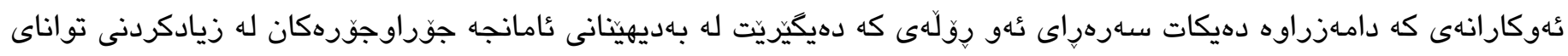
بارهـهمينان و بادهست هينانى تايبهتمهنديهكانى كى بركي.

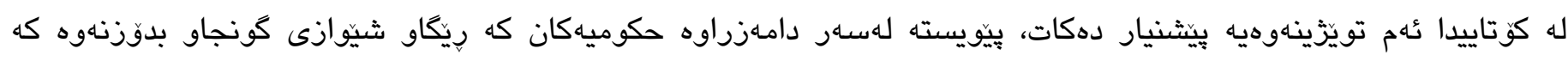
يارمهاتيدهربن بو جِونيهتى بيّوانهكردن و خستنه رووى سهارجاوهى فكرى دارايى له رإيورته داراييهكاندا، بيّويسته لهسهر دامهزراوه حكومياكان كه ههموو خهرجيهكانى سهرجاوهى فكرى دارايى هـزمار نهكات له هـزمارى كوتايى (حساب النتيجة) لهبهرئهوهى سهرجهاوهى فكرى دارايى هـزماردهكريت وهك هـبووهكانى دامهزراوه( الموجودات) نهوهك خهرجيهكانى. كليله وشه. سـهرجاوهى فكرى دارايى، كارتى ئهنجامدانى هاوسهنكى، بِيّوانهكردن، بيردوزهى باسكردن و شيكاركردن 